\title{
Accelerating Biologics Manufacturing by Modeling or: Is Approval under the QbD and PAT Approaches Demanded by Authorities Acceptable without a Digital-Twin?
}

\author{
Steffen Zobel-Roos, Axel Schmidt ${ }^{\mathbb{D}}$, Fabian Mestmäcker, Mourad Mouellef, Maximilian Huter, \\ Lukas Uhlenbrock, Martin Kornecki, Lara Lohmann, Reinhard Ditz and Jochen Strube * \\ Institute for Separation and Process Technology, Clausthal University of Technology, Leibnizstraße 15, \\ D-38678 Clausthal-Zellerfeld, Germany; zobel-roos@itv.tu-clausthal.de (S.Z.-R.); \\ schmidt@itv.tu-clausthal.de (A.S.); mestmaecker@itv.tu-clausthal.de (F.M.); mouellef@itv.tu-clausthal.de (M.M.); \\ huter@itv.tu-clausthal.de (M.H.); uhlenbrock@itv.tu-clausthal.de (L.U.); kornecki@itv.tu-clausthal.de (M.K.); \\ lohmann@itv.tu-clausthal.de (L.L.); ditz@itv.tu-clausthal.de (R.D.) \\ * Correspondence: strube@itv.tu-clausthal.de; Tel.: +49-5323-72-2355
}

Received: 16 November 2018; Accepted: 31 January 2019; Published: 13 February 2019

\begin{abstract}
Innovative biologics, including cell therapeutics, virus-like particles, exosomes, recombinant proteins, and peptides, seem likely to substitute monoclonal antibodies as the main therapeutic entities in manufacturing over the next decades. This molecular variety causes a growing need for a general change of methods as well as mindset in the process development stage, as there are no platform processes available such as those for monoclonal antibodies. Moreover, market competitiveness demands hyper-intensified processes, including accelerated decisions toward batch or continuous operation of dedicated modular plant concepts. This indicates gaps in process comprehension, when operation windows need to be run at the edges of optimization. In this editorial, the authors review and assess potential methods and begin discussing possible solutions throughout the workflow, from process development through piloting to manufacturing operation from their point of view and experience. Especially, the state-of-the-art for modeling in red biotechnology is assessed, clarifying differences and applications of statistical, rigorous physical-chemical based models as well as cost modeling. "Digital-twins" are described and efforts vs. benefits for new applications exemplified, including the regulation-demanded $\mathrm{QbD}$ (quality by design) and PAT (process analytical technology) approaches towards digitalization or industry 4.0 based on advanced process control strategies. Finally, an analysis of the obstacles and possible solutions for any successful and efficient industrialization of innovative methods from process development, through piloting to manufacturing, results in some recommendations. A central question therefore requires attention: Considering that $\mathrm{QbD}$ and PAT have been required by authorities since 2004, can any biologic manufacturing process be approved by the regulatory agencies without being modeled by a "digital-twin" as part of the filing documentation?
\end{abstract}

Keywords: biologics; manufacturing; modeling; continuous bioprocessing; modular plants; process intensification; sustainability

\section{Introduction}

Biologics currently contribute more than $30 \%$ to the pharmaceutical drug market with attractive growth rates [1-9]. Monoclonal antibodies $(\mathrm{mAb})$ contribute now approximately $70 \%$ of the biologics market [4], with a platform technology based, yet improvable production process [10-13]. Moreover, 
market analysis of company pipelines and drug substances in the approval process with regulatory authorities such as the Food and Drug Administration (FDA) and European Medicines Agency (EMA) indicates that a broader variety of novel therapies are moving forward to cope with urging societal needs, e.g., oncology or diabetes, cell therapy, virus-like particles (VLP), exosomes, Methicillin-resistant Staphylococcus aureus (MRSA) antibiotics and diabetes cures. Surprisingly, this also includes mature processes such as blood plasma fractionation [14-25].

For new process approval, authorities demand quality by design $(\mathrm{QbD})$ and process analytical technology (PAT) since 2004 [26-29].

Besides, most of the established blockbusters face stiff competition from biosimilars, which puts more pressure on cost effectiveness in manufacturing processes [30-32].

One answer is switching towards single-use technologies, whose sustainability has yet to be proven, dedicated modular plant concepts or continuous bioprocessing as well as "hyper-intensified processes", a term created by exaggerated marketing [33-37]. Single-use/disposable technology seems to be a temporary intermediate step towards efficient in-house processes, but the sustainability of a few thousand kilograms of solid waste disposal vs. buffer cleaning costs is questionable in the long run. Proper balancing of the whole value chain seems to be necessary to avoid erroneous investments [10-12,34].

The central challenge is to achieve a "best in class" process design together with cost efficient manufacturing within given timelines of about six months. The new broad molecular variety of drug candidates demands a change in mindset, as one platform process will no longer prevail, which has been the case over the last 10-20 years for mAbs. Thereby, "platforming" has made industrial methods applied in process development relatively simple and no innovation has been pushed to cope with the broader molecular variety until now.

Moreover, the latest $\mathrm{mAb}$ process optimization studies show that process comprehension is increasing within the defined design space, but not as high as assumed and required when driven to the edges as recently observed in hyper-intensified processes.

The industrialization of continuous bioprocessing technologies in manufacturing of biologics has arrived at a stage, where the question of doing it is no longer discussed, but to figure out if sufficient best case studies with lessons learned are known $[35,38,39]$.

Model based methods are increasingly used also in biotechnology [40-42]. Based on fundamentals from chemical engineering [43], at first smaller molecules from white/industrial biotechnology were investigated and are now followed by complex large molecules in red biotechnology [44-46]. A recent review from the upstream processing perspective of process control points out that model-based methods are still not fully exploited in bioprocess technology due to a lack of (i) acceptance by the users, (ii) user-friendly tools provided by existing methods, (iii) implementation in existing process control systems and (iv) clear workflows to set-up a specific process model [46]. This paper enlarges the discussion from the process development and design perspective via piloting towards manufacturing operation through the eyes of process (systems) engineering under the actual regulatory constraints applied for biopharmaceuticals.

Modeling is enabling to accelerate process design from batch to continuous biologics manufacturing for any molecule of interest besides mAbs, such as fragments, VLPs, exosomes, insulin, and antibiotics. Modeling is well established for smaller molecules in the chemical industry by chemical engineering personnel educated and trained in applying those methods. Availability of models and data, either by in-house data-bases or by experimentally standardized setups enable predictive process simulation in order to reduce experimental efforts in process design [47-54].

For biologics process development the demands to reduce experimental efforts in process design for laboratory and piloting are in the range of $10 \%$ in order to be fast and cost efficient. Here, modeling, in other words a sound quantitative theoretical process comprehension, is the only known method on hand. The open question is, whether the larger molecular complexity of biologics permits to easily adapt methods and lessons that have already been learned in the chemical industry decades ago. 
Lessons learned in chemical industry by establishing modeling are:

1. A database of physical properties is needed with in-house data on product related molecular process knowledge. Experimental methods have to be standardized in laboratories and thermodynamics experts need to maintain such a database and be expert advisors for modeling colleagues. The value of such in-house data is tremendous.

2. Data need to provide accuracy and precision, which can be directly predefined by modeling.

3. To build up reliable databases takes time. Each new molecular system has to be experimentally assessed with regard to physical properties for the unit operations feasible.

4. Additional modeling and simulation methods require, of course, additional efforts and resources, i.e., costs. Those investments easily pay off if a reduction of experimental effort is achieved. As pilot run costs are quite high and time consuming, the easiest approach is to involve simulation experts into the piloting runs. A side benefit is that models can remain less complex as the colleagues are directly involved in process operation reality and the required measurement accuracy.

5. Models derived in process development with miniaturized model parameter determination in laboratory scale follow clear workflows/recipes i.e., standard operation procedures (SOP). Direct benefits are gained if those models support piloting runs for experimental validation and afterwards move the product into engineering for equipment plant design and advanced process control concepts over the lifetime into manufacturing operation for process robustness analysis.

6. Time reduction in process development is achieved by running the experimental plans for model parameter determination for each unit operation in parallel. Of course, the analytical methods have to be available and run in parallel for all methods considered. This may speed up conceptual process design towards experimental feasibility to less than a month for a well-trained interdisciplinary team.

7. Necessary team know-how should include chemical engineering for model development. In addition, technicians running analytics and laboratory scale equipment for experimental model parameter determination should be trained on accuracy and precision needed for those experimental plans which differ from classical design of experiments (DoE) setups. Such laboratory scale equipment should ideally already be equipped with process analytical technology (PAT) methodologies and in addition with fractionation devices for sampling to quality assurance (QA).

In conclusion, a summary statement of the authors is that models are available for all unit operations. Model parameter determination concepts are quantitative, distinct, and efficient in daily project work. Applicability of these concepts to the scenarios on hand is proved in the following in detail, and in addition supported by some case studies.

For precision of argumentation, the term "modeling" used in this context includes all steps of product and process development up to monitoring of the manufacturing operation using different modeling types as laid out in Figure 1.

Product development uses artificial intelligence methods such as data mining for drug discovery data analysis, drug target interactions, and pharmacokinetics are quite well established with aid of modeling covering molecular interactions [55-57].

Multi-scale modeling along the workflow of process development, piloting, engineering, and production taking into account the life cycle management needs to add on large scales statistical design of experiments, cost estimation methods, and rigorous process modeling towards engineering. Advanced process control concepts integrate either observer models or artificial intelligence elements such as neuronal networks and data mining. Phase equilibrium and mass transfer kinetics data is gained independently of scale in laboratory scale. In addition, fluid dynamics need to be determined dependent of scale and equipment design, which will be integrated in modular modeling approaches such as rigorous process models. Due to that, this is the only modeling type predictive in scale. 
Manufacturing know-how adds from production scale cost structures and large scale fluid dynamics data needed early in process development. Only in manufacturing scale any profit is finally gained by application of the methods. This requires a priori acceptance of those methods in industrial practice. Fluid dynamics of equipment could be added by aid of vendor data for skids and modules. Statistical methods are applied besides DoE for regression of PAT data sets by principal component analysis (PCA) or partial least squares regression (PLS). Automation workflow integrates advanced process control methods such as observers, rigorous process models, or neuronal networks together with information technology, which add interfaces and architectures for sensors, scheduling, maintenance and supply chain analyses.

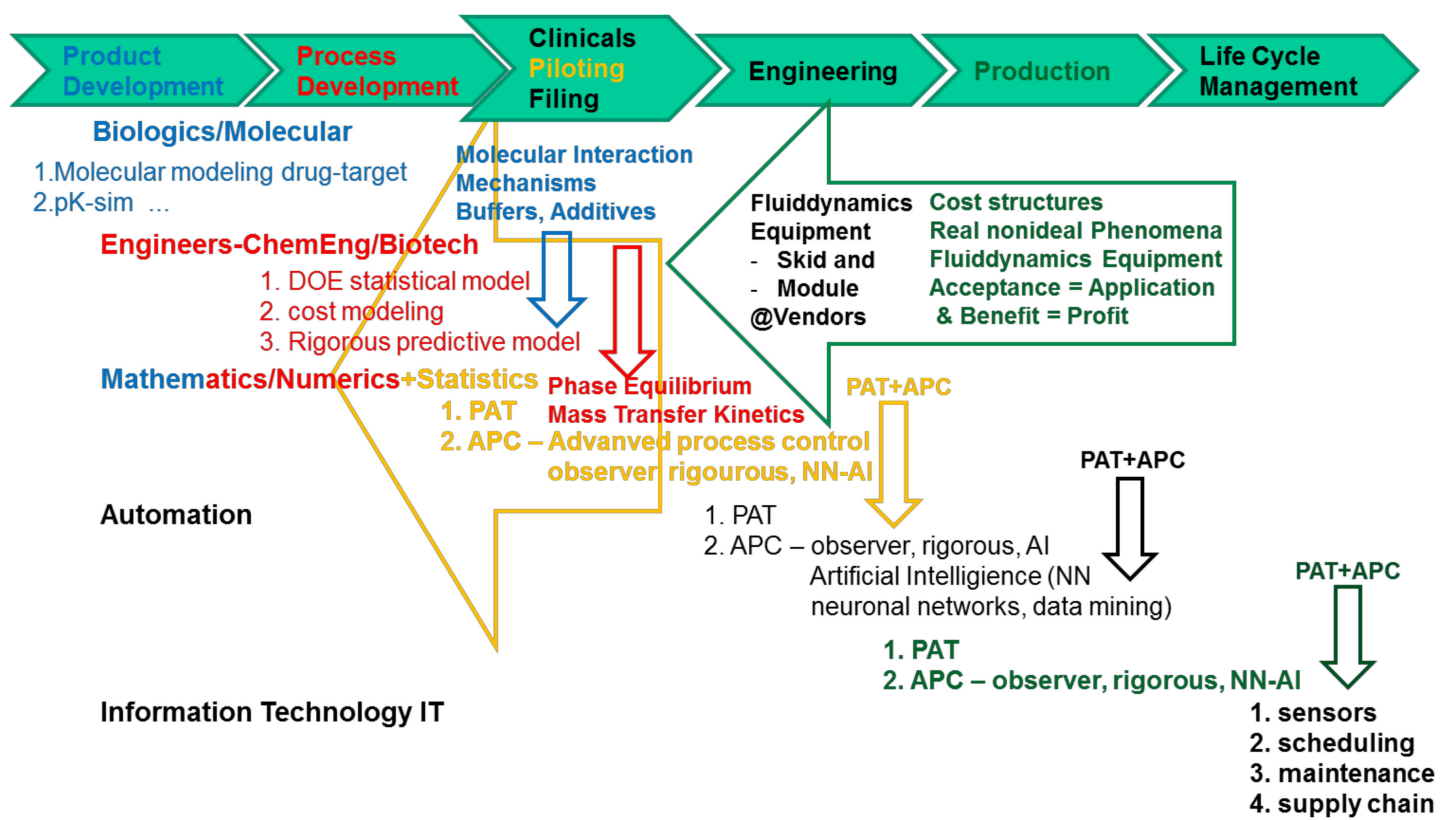

Figure 1. Overview of modeling types in different stages of process development and life cycle.

Figure 1 depicts modeling types from drug design workflow all the way to manufacturing support.

Basic rule in any modeling discussion, in order to be precise, is to use the wording "model/modeling" only in combination with the model type and not alone. One common definition in chemical engineering is that "a model is an object, which is based on a structure or functional analogy to a subsequent original is utilized to build a special task for the original". The object is then a model of the original, if analogies between object and original are existing and the analogies allow to draw conclusions towards the original."

Minsky created a definition, which explains the specifics of a model towards the original in more detail: "To an observer $B$ and object $\mathrm{M}$ is a model of an object $\mathrm{A}$ to the extent that $\mathrm{B}$ can use $\mathrm{M}$ to answer questions that interest him about A." Concluding, a model is created by structure or functional analogy to an original for a specific task and is very task specific. There is not a single model of an original. Modeling is dedicated to the task-orientated reduction of reality, which is objectively noticed. The subjective reality is linked to any unknowing abstraction as well as interpretation of the perceived by any observer [58].

Therefore, all model types are defined appropriately for clarification of any discussion towards a digital twin of any manufacturing plant.

Digital twin: A digital twin is defined as the predictive and validated model of the manufacturing process with the intention to support approval documentation. Any post-approval changes are possible and organized according to [59-61]. Therefore, the only model type appropriate to generate a digital twin is a rigorous physical-chemical based process model. A model not covering the manufacturing process and equipment in total has therefore to be considered insufficient. Digital twin is a digital, i.e., 
virtual copy of a real manufacturing plant in operation, in order to predict and organize maintenance and life cycle management efficiently. However, a twin should be born almost at the same time and from the same parents. Therefore, digital copy seems more precise, because actually digital twins are created roughly within a 2 year time-span during plant erection and operation afterwards. Under regulatory constraints utilizing a digital twin with regard to process performance, i.e., naturally related to product quality, robustness and safety, requires the twin to be born at the same time and not as a copy. Concluding, digital twin is correctly phrased under pharmaceutical constraints, the first born.

If you define a digital twin by training e.g., AI-tools such as neuronal networks which are advanced statistical models trained by process operation data sets, it implies that process design is completed and a plant is already operated. Therefore, it is too late to be a tool for process design, which would be needed in advance for regulatory approval and efforts reduction in early process design.

Stationary and dynamic digital twins are known as part of the IOT (internet of things). A manufacturing plant twin takes about two years for configuration to be able to support maintenance and life cycle management [62].

According to the literature [63-65], a digital twin is referred to a real time optimization and life cycle support of products by generating a data driven copy of the real manufacturing plant i.e., the process operation parameters and the equipment used.

This in consequence means that the original process is already approved, built within equipment specs and operated. With this narrow definition a digital twin would not be available for process design and regulatory approval documentation. Therefore, it would be useless in biologics drugs manufacturing for establishing a workflow. Final production of an appropriately designed and approved manufacturing process is an issue for advanced process control under PAT support.

A digital twin due to this limited definition generated in non-strictly regulated industries such as energy generation or automotive manufacturing is a digital copy of a conventionally designed, validated and implemented process - this would be a very limited tool in regulated industries.

Secondly, if the process is operated and therefore has been approved, then a digital twin in order to be used under regulatory constraints needs to have been approved as well prior to its use-which is generally not possible, as such twins in the narrow process control based definition of automation vendors-are not existing in a process development and design environment, where data for approval purposes is generated.

Hybrid modeling: Hybrid means by definition that each part contributes to the objective. However, in hybrid modeling the hybrid part i.e., the artificial intelligence i.e., the statistical model, which statistically summarizes parts of the model, which could not be described rigorously, destroys the beauty and usefulness in application of the rigorous model completely. A description is achieved, but no prediction. This is due to the replacement of former rigorous by statistical parts. Exemplified, some mechanism part such as phase equilibrium isotherms are replaced with neuronal networks. Nevertheless, efforts and trainings data are needed as well $[66,67]$.

Statistical models: Are part of the evaluation of experimental data generated according to DoE experimental plans, which could be statistically evaluated according to accuracy and prediction by aid of statistical models [51,68].

Artificial Intelligence (AI): There are two general opposed opinions, the Dreyfus [69] and Domingos [70] schools. Intelligence does mean creative. However, with a weak AI those models are creative by definition only within a given training setup. Sound science needs to always differ between training setup data and data sets which should not belong to the training setup to control model precision and accuracy-nevertheless, the range of those data sets needs to be within the trainings setup data range, because those models such as neuronal networks are NOT predictive or creative outside the training data sets $[69,71]$.

Learning systems such as AI provide opportunity and challenge. Discussion is still whether they are to be called intelligent or not; depending of course on how huge the creativity criteria are emphasized [69,70,72-74]. Nevertheless, in chemical engineering AI is mostly dedicated to machine 
learning and further-on deep learning i.e., in majority to neural networks and data mining tools [75-77]. In pharmaceutical industry, expectations rank from big data mining analysis in drug development up to neuronal networks trained by operational data and used to predict maintenance, life cycles or operational parameter ranges [78-81]. Learning needs training data sets and the prediction quality is dominated by the variety and accuracy of those data sets. Variety is not liked for manufacturing data in regulated industries, neither by process design nor by approval. Nevertheless, those statistical tools are a major aid in maintenance planning and prediction [82,83]. Moreover, this equipment related data is of use for down-scale or up-scale predictions [84,85].

PCA/PLS regression models: PAT methods are run either off line, at line or at best in line such as the ATR-FTIR, Raman, mass spectrometry (MS), etc. These are measurements or in other words, analytics. This is definitely not modeling, apart from a PCA/PLS regression model which is established by the use of training data sets from component spectra or chemometrics data bases. Therefore, this is NOT modeling but regression data analysis.

Table 1 summarizes those arguments and differences, green are predictive process models highlighted whereas red are non-predictive.

Analytics should be transferred from product development along the workflow towards process development over piloting towards manufacturing with continuous improvements. Besides, in addition QA analytics are in general well established already in early product development.

Fundamental laws are followed by rigorous i.e., physical-chemical mechanism based modeling by separating the contributing effects of fluid-dynamics, phase equilibrium, and mass transfer kinetics as well as energy balances, if needed. The benefit is that such models are predictive whereas black-box, short-cut or even stage or cell models are definitely not. The beauty of such an approach is in addition, that the setup of equations could be completed distinctly and stepwise. The logical order is to describe at first fluid dynamics of equipment and modules, then add phase equilibrium, if needed with temperature dependency and energy balances, and finally the mass transfer resistance mechanisms for completion.

Basic law is that phase equilibrium and mass transfer are independent of equipment size and can therefore be determined in miniaturized laboratory scale. Helpful for experimental model parameter accuracy of those laboratory data is that they are determined directly without any simplifications with aid of the model steps which demands that fluid dynamics of laboratory size equipment has to be determined at first and integrated within those models. The only difference in scale is then caused by fluid dynamics, which leads to the consequence that fluid dynamics of pilot and manufacturing equipment must be determined as well and be integrated as model parameter setups in those models. This procedure takes into account that besides liquid-liquid extraction all other unit operations do lose in scale-up some specific operation performance caused by increasing fluid dynamic disorder in larger scale.

Manufacturing companies are recommended to define prior to procurement for potential equipment vendors to measure fluid dynamics tests of equipment skids and devices and define value and acceptable variance for dispersion, holdup and pressure drop, residence time distribution, pressure-flow curves. This could easily be done during factory and site acceptance testing in operation qualification (OQ) for new equipment and plants. Existing plant and equipment or modules could be characterized sufficiently by direct statistical evaluation of current operation data [82,83].

Modular plant design relates to operate for scale up modules in parallel. Such operation needs reproducible pressure flow curves for the different devices in parallel in order to distribute the fluid really equally i.e., $+/-8 \%$ for selective bind-and-elute capture steps such as protein $\mathrm{A}$, but less than $+/-3 \%$ for selective elution steps such as ion exchange chromatography (IEX), hydrophobic interaction chromatography (HIC) etc. 
Table 1. Model types definition, required input and falsification from process engineering point of view (PCA: principal component analysis; PLS: partial least squares regression; APC: advanced process control).

\begin{tabular}{|c|c|c|c|}
\hline Process Model Type & Definition & Required Input & Falsification \\
\hline Rigorous & $\begin{array}{l}\text { taking all relevant physical-chemical process effects of } \\
\text { fluid dynamics, phase equilibrium and mass transfer into } \\
\text { account by separating those effects from each other }\end{array}$ & $\begin{array}{l}\text { 1. experimental model parameter determination with separated effects } \\
\text { of fluid dynamics, phase equilibrium and mass transfer } \\
-\end{array}$ & $\begin{array}{l}\text { short-cut models, statistical models, } \\
\text { hybrid models }\end{array}$ \\
\hline Short-cut & 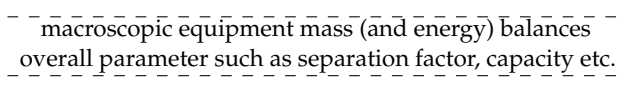 & $\begin{array}{l}-\ldots-1 . \\
-\end{array}$ & physical chemical effects not all separated and ${ }^{-}$ \\
\hline Cost modelling & $\begin{array}{l}\text { use short cut models add cost correlations for operation } \\
\text { and investment costs }\end{array}$ & $\begin{array}{l}- \\
-\end{array}$ & better name: cost estimation \\
\hline Hybrid models & $\begin{array}{l}\text { combining short-cut or rigorous models with } \\
\text { statistical parts }\end{array}$ & 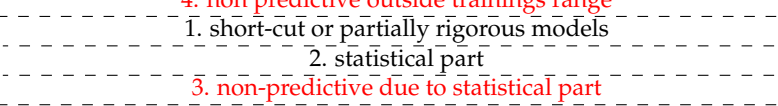 & nonsense \\
\hline & & $\begin{array}{l}\text { 1. operation data sets } \\
\text { nats }\end{array}$ & 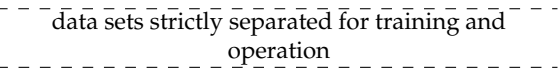 \\
\hline Observer models & for process control statistically trained & 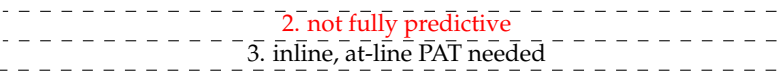 & - sensor drifts cause problems \\
\hline $\begin{array}{l}\text { Modei based }{ }^{-} \\
\text {process control }\end{array}$ & belong to advanced process control & 1. rigorous models & 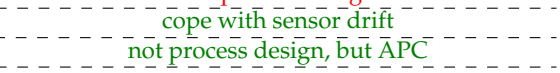 \\
\hline $\begin{array}{l}{ }^{--} \overline{\mathrm{P}} \bar{C} A^{-} / \overline{\mathrm{P}} \overline{L S}^{--} \\
\text {regression model }\end{array}$ & statistical model for analytical description & 1. analytical data sets & no model but analytics data regression equation \\
\hline Artificial intelligence & mostly neuronal networks & 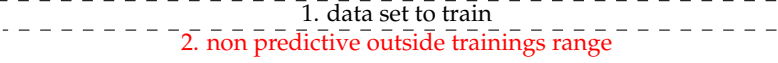 & \\
\hline
\end{tabular}


Such full and consistent documentation of manufacturing data will allow an appropriate scale-down over piloting towards process development-always following the key-objective to predict manufacturing scale correctly.

\section{Challenges with Regard to Models and Modeling}

Addressing the challenges in industrialization of the digital-twin concept towards digitalization or industry 4.0 some obstacles may occur:

1. At least three general model types have been defined before

a. Physical-chemical based rigorous models

b. Cost modeling i.e., cost estimation and

c. (Advanced) process control e.g., statistical observers, neuronal networks and data mining as parts of artificial intelligence

Regression models of analytical data are left out. Each model type has its benefits and place within the workflow. They are totally different and should not be mismatched.

2. Cost modeling [86-90] is based on simple mass and component as well as macroscopic energy balances if needed. Data is taken from experimental operation of the units. Cost modeling is based more on classical flowsheet balancing than real modeling, therefore, in chemical engineering graduation it is called cost estimation (class 1-5) [91,92].

3. Increasing modeling depth does not necessarily increase accuracy of prediction if the model parameters involved could not be determined sufficiently precise. Any model is a look at the specific view of its predefined aim from the point of view of the model developer with the needed, but of course limited accuracy towards a complex reality. Nevertheless, sufficient for the task. Therefore, objectives and accuracy have to be thoroughly defined first.

4. Process control methods are well established in chemical engineering and industry. BASF reports to benefit from additional observer model training during plant start-up even with regard to the corresponding delay of manufacturing begin of about 3 months [93]. Those, observer or advanced process control methods based on statistics, such as artificial intelligence tools such as neuronal networks, are generally valid and available, which could be directly transferred to biologics operation. In line sensors are in most cases efficient, but there is the major challenge to cope with their natural drift.

5. Here, again rigorous models—available already from process development with appropriate efficient organization - are the methodological solution of choice.

6. The models discussed are available, all three of them. Any prejudices have to be rejected: Rigorous modeling of all unit operations needed for total process integration are on hand, as proven later on.

7. Determination of model parameter data follows a distinct concept to guarantee accuracy and precision needed as well as the independence of each mechanism contributing within the model.

8. Models are based on theory—and experiments! (as described above)—and industrial acceptance for theory is only given if it is validated by reality. Therefore, a distinct workflow with quantitative decision criteria is needed for model validation. This has been proposed and applied successfully [94-96] - and is available.

9. Just to summarize and point out the argumentation line in reverse for precision: How could under the mindset of $\mathrm{QbD}$ and PAT demanded by authorities since 2004 [26-29] any process be regulatory filled and accepted which has NOT been properly modeled?

10. An additional motivation for companies to industrialize modeling in biologics manufacturing should be the value of ownership of product related manufacturing data summarizing knowledge and experience of many hundreds, even thousands of man years, being a core asset for any 
manufacturing company. Moreover, taking into account that e.g., Samsung has already invested in 3 custom manufacturing organization (CMO) plants means that a more IT-based big-consortium company has direct access to manufacturing data [97]. Other IT-based companies even more dedicated to artificial intelligence may join that strategy of getting data access and generating value by product diversification.

\section{Post-approval changes:}

Major, moderate, and minor post-approval changes have to be categorized and different actions to be taken. Any product quality related issues are major changes which may cause additional clinical trials. Any modification has to be discussed and documented based on data regarding the assessment of the effect of the changes, either to conformance of specification or additional testing. Evaluation of changes of impurity profiles to already approved specification and adverse effects do have to be tested and documented. Equivalence, which does not mean identity but is related to maintenance of a quality characteristic rather than a single performance test.

General objective of any accepted post-approval change should be an improvement which has to be quantified and the potential with regard to the risk be assessed, e.g., by aid of appropriate risk analysis.

Any addition to PAT tools and AI manufacturing data evaluation which are used to take decisions in manufacturing operation should be regarded as major changes as they do have a complex multi-causal impact on product specification. Therefore, the need for additional clinical trial studies may be high or vice versa such general methods should be already implemented in early process development for supply of first clinical batches which are part of the approval procedure already [59-61].

\section{Solutions}

Derived from that analysis some recommendations for organizational adjustments within companies could be derived as basic rules to gain acceptance and economic benefits from applying those methods:

1. Any interdisciplinary team must be set up to cover the following knowledge, background, and skills, see Figure 2:

- Biochemistry/Biotechnology for chemometrics on the molecular level for PAT sensors and PCA/PLS regression models, metabolomics for USP (up-stream processing) modeling

- Mathematics to support numerical solutions of process modeling, transferring models from process development towards engineering i.e., advanced (model-based) process control

- Statistical expertise for DoE design in process development, as well as regression modeling in analytical PAT via PCA/PLS

- Engineering i.e., Chemical/Biotechnology Engineering for process modeling combined with experimental model parameter determination in miniaturized laboratory scale, model validation experiments and process development and design

- as well as for operation of process development laboratory scale-down equipment automated and PAT equipped, piloting and manufacturing

- PAT sensor implementation

- Automation/process control system design including advanced process control and process analytical technology

- $\quad$ IT-experts for protocols, data bases, data access, interfaces, safety and security

2. The largest challenge seems to be the necessary change in mind-set. Well established procedures and habits have to be changed by process modeling combined with experimental model parameter determination-instead of full experimental process development. The challenge lies not in 
manufacturing or piloting but in process development. This is a lesson learned from chemical industry in recent years/decades [45].

3. Access to data must be organized. To provide long-term development, an internal database is recommended, which must be maintained by experts who support the simulation team with recommendations and measurements for data quality control. Setting up any in-house cloud seems to be the key value-asset of any company future.

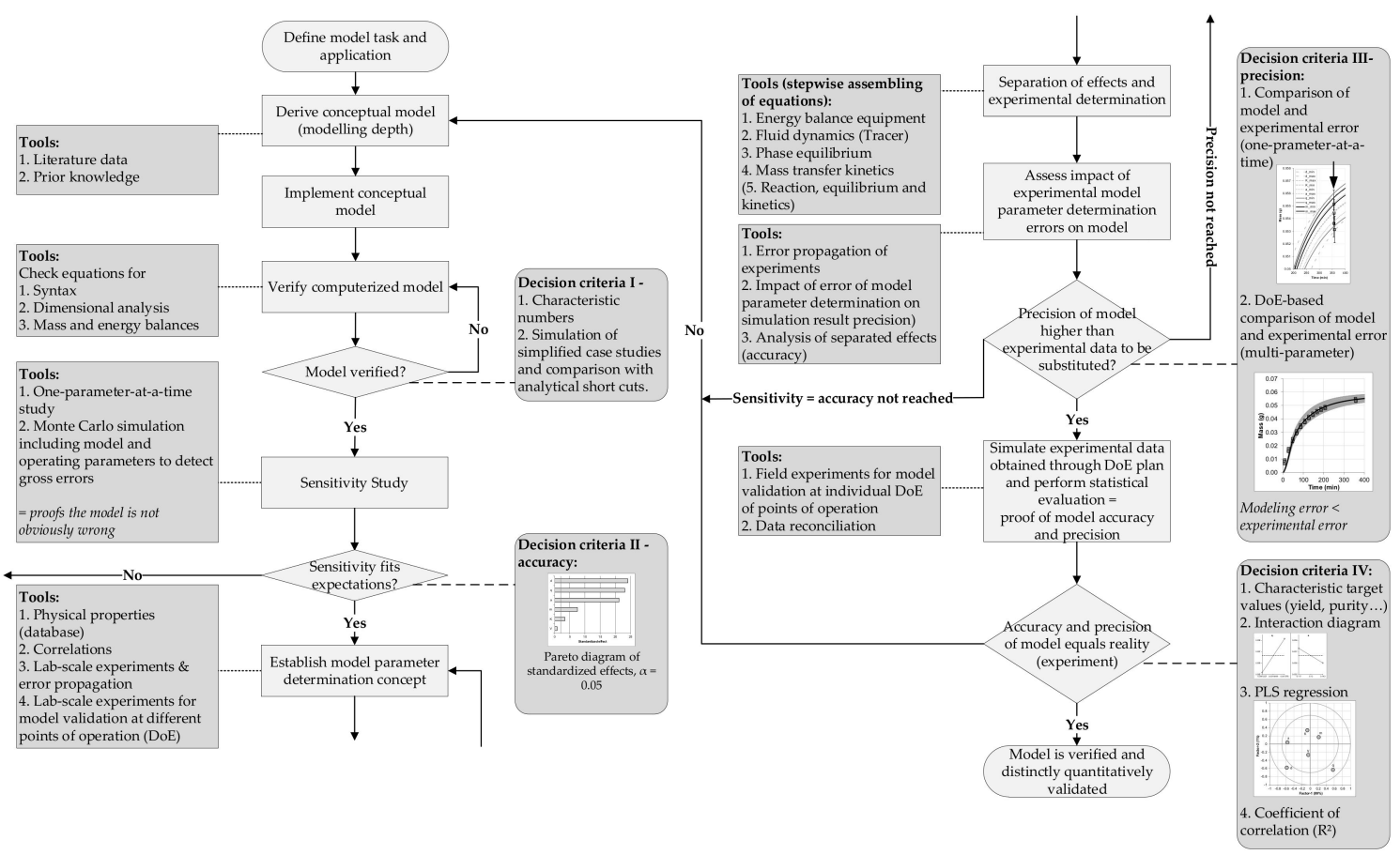

Figure 2. Process design and operation model validation method [94].

Moreover, some basic prejudices against modeling must be dispelled data driven:

\section{Model derivation:}

Any model must be experimentally validated and quantitatively defined in terms of accuracy and precision, to gain industrial acceptance for making decisions based on theory.

Such methods are available, e.g., see Sixt et al. 2018 [94]. Figure 2 exemplifies a general valid workflow with clear quantitative decision criteria and next work steps.

This workflow presents a clear and general approach to model definition, implementation, verification and validation, including the evaluation of model precision and accuracy [94,95]. Figure 2 contains relevant tools and decision criteria, for tasks and evaluation, suitable for small and medium enterprises as routine method.

First step of the workflow is the definition of the model task. Subsequently, a conceptual model is derived. As a first decision criterion, characteristic numbers, such as Reynolds, Péclet, Sherwood or Schmidt, are compared to literature data. Subsequently, model sensitivity is assessed and compared to experimental studies (DoE) to ensure correct representation of reality.

The next step is the development of a consistent model parameter determination concept. At this stage, different tools are practicable, e.g., databases, correlations and lab-scale experiments. The separation of different effects, for example energy balance, fluid dynamics, phase equilibrium, mass transfer kinetics etc., allows the stepwise assembly of model equations.

Error propagation of model parameter determination has to ensure adequate precision and accuracy of the model. The model error, including the error from model parameter determination, has to be smaller than the error from experimental process characterization, to allow for the substitution of experimental data by rigorous process modeling. 
The last and most significant step is model validation, using independent field experiments. These consistent data sets can be analyzed due to target values (yield, purity etc.), parameter range and their sensitivity regarding analogous simulation data setups. If yield, purity, space-time-yield, specific auxiliary/energy amount, and parameter interactions are in an identical order of magnitude of correlation coefficients in the PLS regression, then the model is distinctly quantitative proven to be valid for its at first defined task and application.

\section{Total process modeling}

The process model must describe the total process to be of use. Such process steps are available as shown in the following as a review. Figure 3 gives an overview about all process step unit operations.

Process Design (in-silico for digital twin generation, validated, predictive)

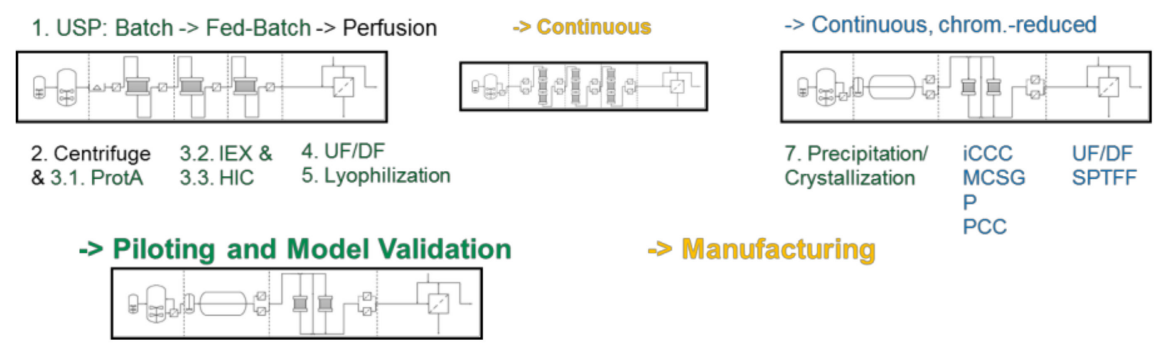

Figure 3. Total process modeling-a digital twin for regulatory support.

Figure 3 exemplifies the process development workflow. Model parameter data has to be measured only once, in batch mode and all available analytics are applied for any component of interest. Based on the models derived all process scenarios are calculated and evaluated by cost estimation routines:

1. a. At first, standardized laboratory equipment is used for each unit operation such as upstream fermentation (USP), Ultra-/Diafiltration (UF/DF), one or many chromatography steps, aqueous two-phase extraction (ATPE), precipitation or crystallization, as well as final lyophilization.

b. This includes PAT-tools for model parameter determination and application of a DoE setup in the scale of few liters' fermentation, few $100 \mathrm{~cm}^{2}$ membrane area and chromatography column volumes of few $10-100 \mathrm{ml}$.

2. An existing DoE with risk analysis is applied for QbD-documentation and to validate the modeling and model parameter determination concept

3. based on the validated process models process design studies with cost evaluations are performed.

a. This leads to a decision for a best-in-class process in silico a priori, which

b. $\quad$ is finally experimentally validated at pilot-scale to prove technical feasibility.

4. In addition, PAT and advanced process control (APC) concepts developed in process design are transferred via piloting towards manufacturing. Vendor may supply fluid dynamics data from skid and module acceptance tests [34,94].

Figure 4 depicts the basic principle, that phase equilibrium and mass transfer kinetics are constant and independent of scale for defined feed and auxiliaries, media utilized. However, fluid dynamics of equipment skid, piping and modules differ in scale. Therefore, this needs to be quantified at scales and implemented at different model parameter data sets in the independent fluid dynamic partition of the model equations. Any linear scale-up/-down gives optimization potential away, because in small scale performance is normally better due to increasing non-idealities and fluid dynamic mal-distribution ratio at larger scale. Nevertheless, dead volume ratio of skid and piping equipment parts towards 
functional module parts (i.e., columns, membranes etc.) is worst at laboratory scale and has therefore to be taken accurately into account for appropriate scale-up [98-102].

As follows, all units along the process are described briefly to prove the statement of availability and project acceptable efforts as well as any references to deepening literature quoted. Any unit operation model can be used in any process flowsheet sequence of interest for total process simulations. The single unit operations and their workflow for model-parameter determination as well as model validation is described in detail within this special issue with at least one article each. Here, an overview is given.
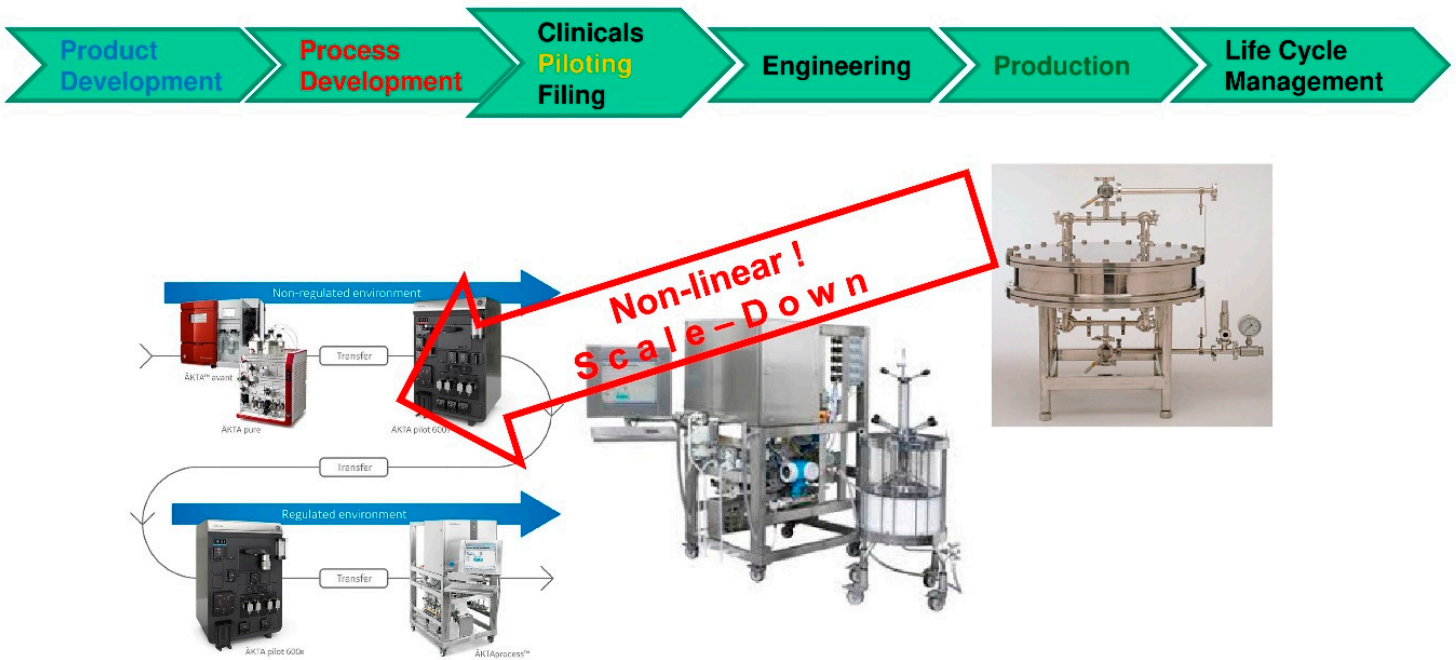

Figure 4. Scale-up and -down via process modeling.

\subsection{USP Fermentation Fed-Batch and Perfusion}

Fermentation modeling and process design is shown in Figure 5.

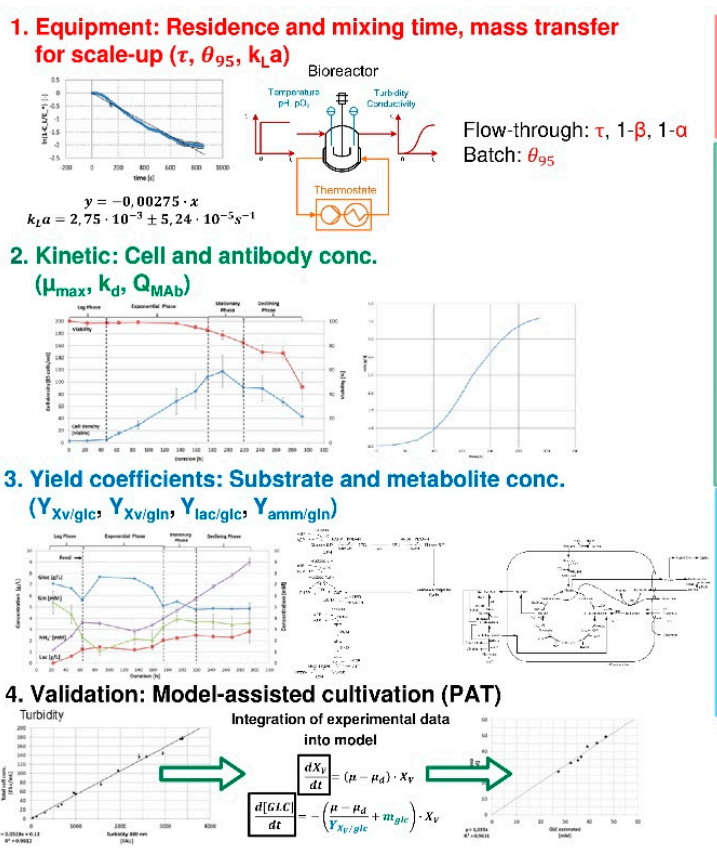

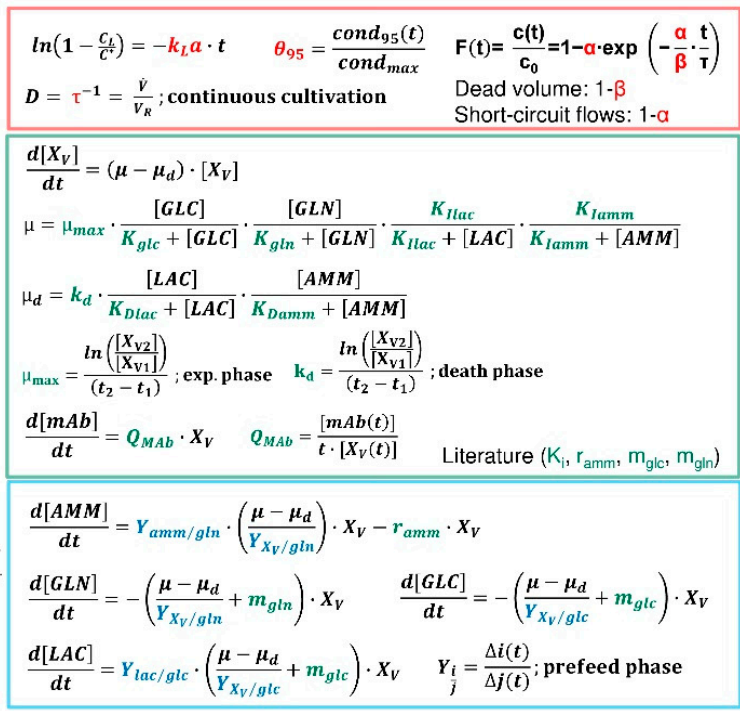

Figure 5. Upstream Processing (USP)—Fermentation Batch/Fed-batch/Perfusion—process modeling workflow, recipe, standard operation procedure (SOP). 
The modeling approach for fed-batch and perfusion cultivation processes is summarized in Figure 5. The main equations are represented by a Monod kinetic, considering the time-dependent alteration of substrate (e.g., glucose, glutamine, etc.), metabolite (e.g., lactate, ammonium, etc.), cell and product concentration. The correlation between input (e.g., substrate concentration) and output (e.g., cell concentration) variables can be macroscopically determined by using empirical observations, such as yield coefficients, which are strongly dependent on the cell line [42].

In terms of 1 . fluid dynamics (red-marked parameters), the determination of oxygen transfer rates according to the unsteady-state (dynamic) technique, mixing time with conductivity measurements as well as residence time with tracer experiments lead to the characterization of the equipment.

To determine 2. kinetic (green-marked, e.g., maximum growth rate) and 3. equilibrium (blue-marked, e.g., yield coefficients) parameters, cultivations as well as the analysis of substrate, metabolite, cell and product concentration need to be performed. The substrate saturation constant (or substrate affinity constant) is equal to the concentration that supports a half-maximum growth rate.

Similar experiments can be used for 4 . validation. Furthermore, online model-assisted cultivation increases the gain in process information by integrating process data (e.g., turbidity) into the macroscopic kinetic model to extract information on process variables (e.g., glucose and lactate concentration) [52].

Efforts are 2 to 3 weeks for cultivation and analysis i.e., 2 to 3 cultivations simultaneously a 1-2 L scale [52].

\subsection{Capture, LLE, Cell Separation and Clarification}

The workflow to determine model parameters needed for a physico-chemical liquid-liquid extraction (LLE) process model is shown in Figure 6. Here, the focus is on extraction columns and mixer-settlers as those cover most of the possible process implementations for LLE. For the sake of completeness, it should be stated that innovative technologies such as membrane-supported LLE or side technology such as centrifugal extractors also exist, for which correct physico-chemical-modeling however follows the same rationale and only has to account for the difference in fundamental geometry and fluid dynamics. This again, is the striking advantage of this model-type, if compared to the other (cost/shortcut-, statistical/observer models). As for any unit operations the sequence to determine these parameters are ordered according to their importance/impact on the process result, which is:

1. Fluid dynamics (red): This is the most important group of effects, which is not only predominantly responsible for the differences in performance of different types of extraction equipment, but also for the differences within the same equipment type (e.g., stirred vs pulsed vs static extraction columns).

Most important phenomena are the axial dispersion behavior of the system, characterized by the axial dispersion coefficient as well as the hold-up, characterized by drop rise velocity, mean droplet diameter and throughput $\left(\mathrm{m}^{3} / \mathrm{m}^{2} / \mathrm{h}\right)$. Axial dispersion has to be determined for the specific equipment geometry, but only once as it is dependent on the geometry, but not the different types of systems that can be processed/modeled. The determination of axial dispersion behavior needs around 2-5 L of total system volume depending on the investigated scale, however does not require the usage of actual feed material. This procedure can be finished within 1 day by an experienced operator. To keep the resource and time benefit of physico-chemical model-based process design the equipment size should not exceed DN26/32 for extraction columns and DN50 for mixer-settlers, which is typical mini-plant scale.

Drop rise velocity depending on mean Sauter diameter are to be determined in a droplet measurement cell, few $\mathrm{mL}$ up to $50 \mathrm{~mL}$ are sufficient to determine these parameters in triplicate for a range of 3 to 5 points of drop size within 1 up to 2 days.

2. Phase equilibrium (blue): Determination of binodale, tie-lines, and distribution coefficients of target and main side components is done by shaking-flask experiments. This standard procedure can be down-scaled to system volumes of 5-10 mL each. Further scale-down is only recommended, if data for interfacial tension, viscosities and densities for both phases are known or accessible by reliable database or correlation. Time and feed material consumption can be drastically reduced by narrowing 
the relevant system combinations by rationale such as kosmotropic/chaotropic properties of the phase forming salts of choice and the hydrophobic/free volume excluding effects of the polymers of choice, which is mostly dependent on the molecular weight and relevant $\mathrm{pH}$ range for the target component. The total number of investigated system points should be narrowed by DoE. This leads to, e.g., 3 systems with 5 distributed points of investigation. Thus, $75(3 \times 5 \times 5 \mathrm{~mL})$ up to $150(3 \times 5 \times 10 \mathrm{~mL})$ $\mathrm{mL}$ of system volume are sufficient for determination and can be executed within 2 days.

3. Kinetics (green): In LLE the most important kinetic parameter is the mass transfer coefficient. The lower this parameter is, the more time for component separation is required, which if not implemented correctly in any model type, and can lead to an incomplete separation (bad purity/yield) due to underestimated kinetic limitations of the system. This parameter can easily be determined parallel to the drop measurements in the drop measurement cell during the 1- to 2-day period (see fluid dynamics) and thus, only increases the analytical efforts.

The total effort for a complete model parameter determination as described above, is around 3 days up to 1 week and requires only 200 up $300 \mathrm{~mL}$ feed material [52,103-106].

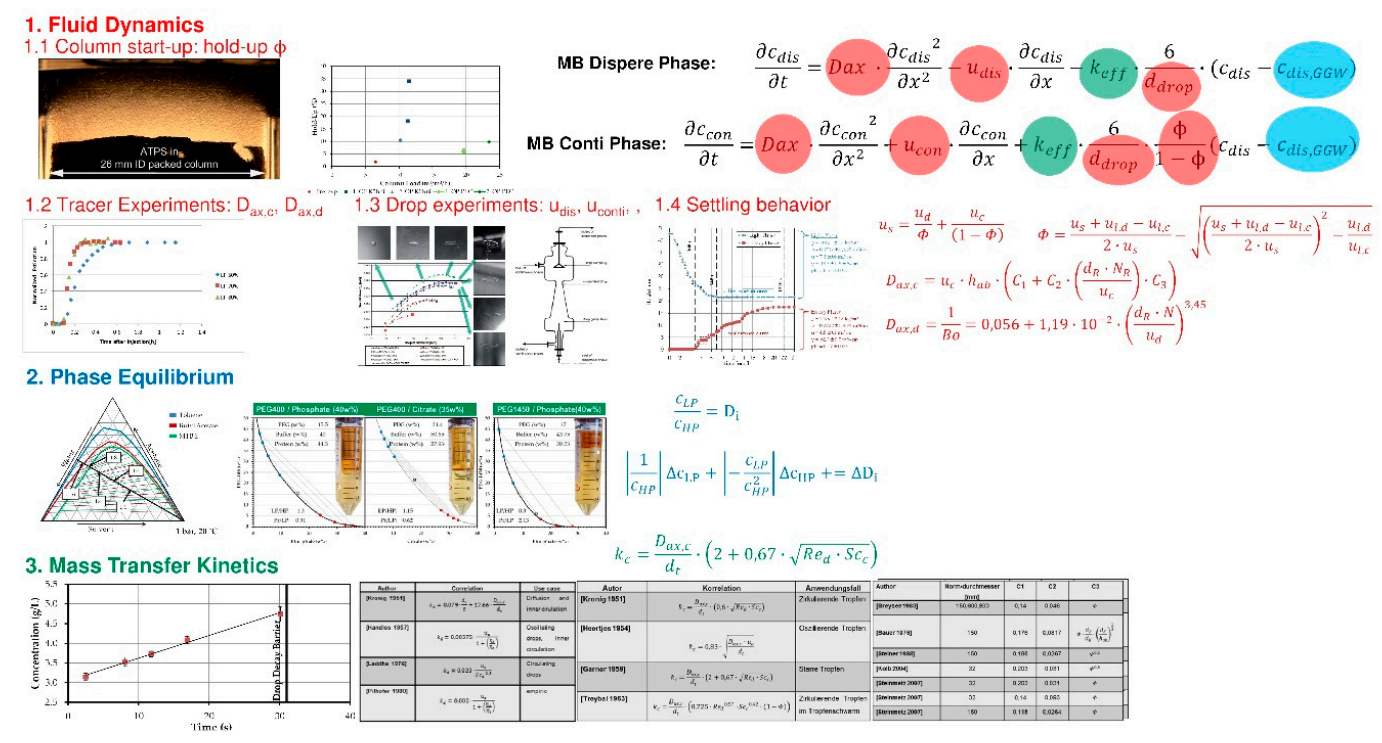

Figure 6. Liquid-Liquid (ATP) Extraction-process modeling workflow, recipe, SOP.

\subsection{UF/DF, SPTFF for Concentration and Buffer Exchange}

To create a model for Ultrafiltration/Diafiltration module- and solution-based information is required. The approach is shown in Figure 7 . The red-marked experiments are needed to characterize 1. the membrane-module fluid dynamics comprising effective membrane area, hydrodynamic diameter and membrane resistance. They are independent from the filtration system and are applicable on other systems as well. The sequential 2. step is the measurement of solution properties (blue). Due to changing density, osmotic pressure and viscosity with increasing protein concentration, filtration behavior varies over time and the values for different protein concentrations have to be quantified as 3 . mass transfer kinetics. After these steps the filtration experiments are performed at different flows, pressures and starting concentrations to 4 . validate the model.

Efforts are 3 days to 1 week requiring $1-100 \mathrm{~g}$ feed material [51,107,108].

The continuous single-pass tangential-filtration (SPTFF) version is analogous, but due to complexity of additional setup variations $[107,108]$.

For the single-pass tangential-filtration (SPTFF, Figure 8) the approach is comparable to batch filtration. The used membrane-modules fluid dynamics have to be 1 . characterized (red) and 2. the solution properties (blue) must be determined likewise to batch filtration. In addition to the batch approach, the influence of stacked membranes has to be investigated. Furthermore, the SPTFF is 
dependent on length, while batch filtration depends on time. This makes 3 . the pressure drop a critical factor, which needs to be investigated. For the research on a SPTFF, a separation of different filtration stages (parallel membrane stacks) is favorable. This provides the possibility to measure the development of process variables over the different stages and enhances process understanding. Validation has to be performed as well as batch filtration for different flows, pressures, concentrations, and in addition for different setups of filtration stages.

Efforts range from 3 days to 2 weeks to properly measure tracer velocities and reproducibility, channel geometries, concentrations, feed pressures as well as setup variation $[107,108]$.

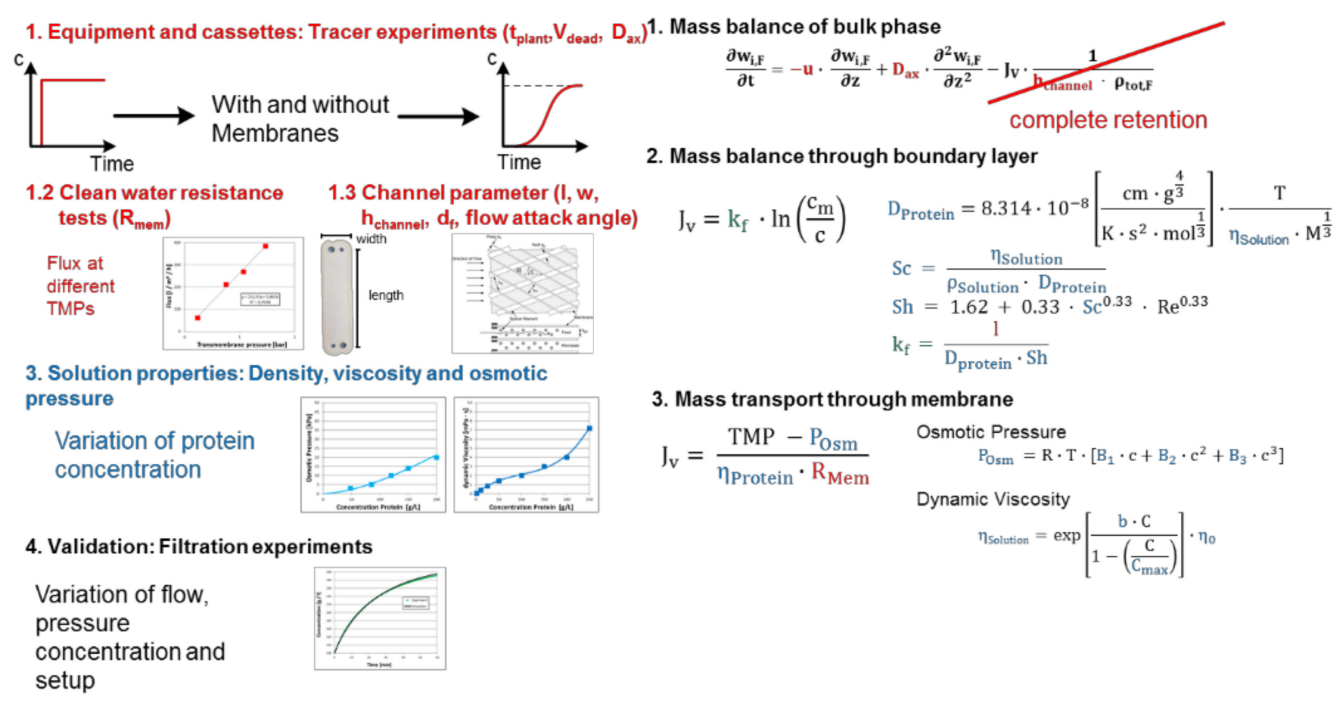

Figure 7. Ultrafiltration/Diafiltration-batch process modeling workflow, recipe, SOP.

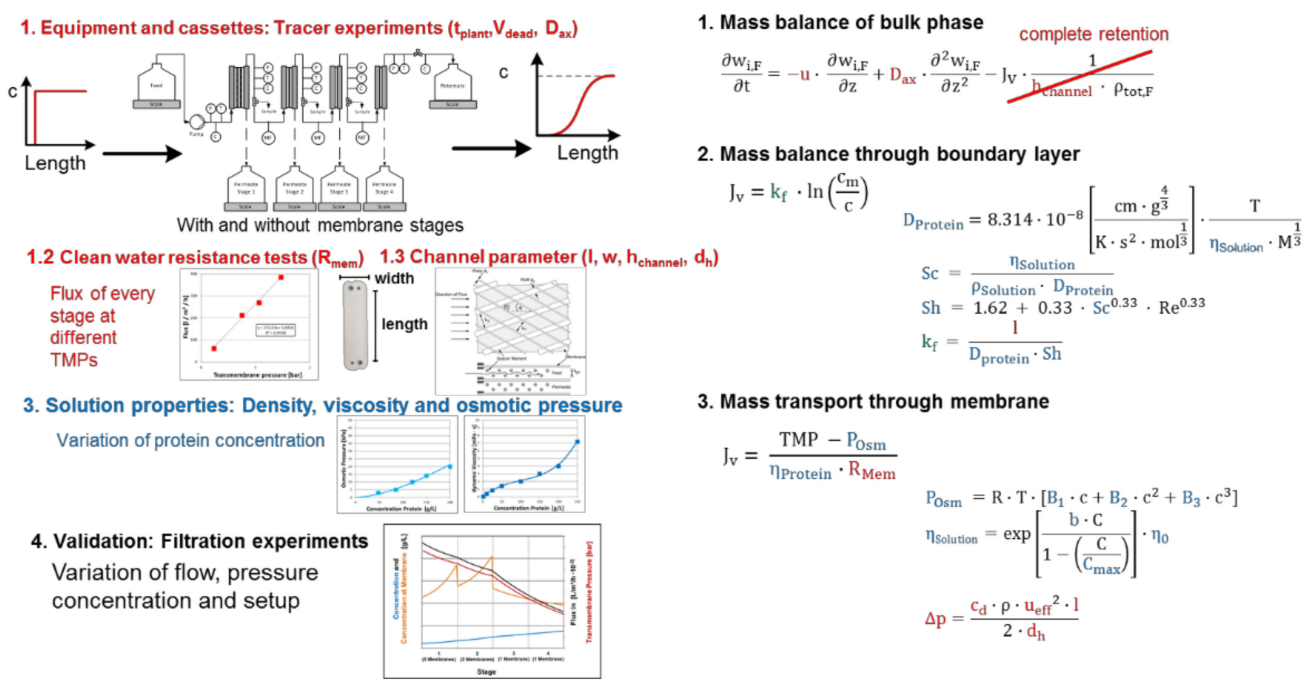

Figure 8. Single-pass tangential-filtration (SPTFF) process modeling workflow, recipe, SOP.

\subsection{Precipitation/Crystallization}

This modeling approach for precipitation, which is shown in Figure 9, is based on a former approach for crystallization [109], but with additional agglomeration and breakage kinetics. Due to the fact, that precipitation also is the result of a shift in solubility 1 . the apparatus fluid dynamics is likewise characterized by residence and mixing time as well as energy balance and solubility of the target component in the system utilized (red). 
Further, 2. mass balance and kinetics of precipitation such as growth, nucleation, agglomeration and disruption have to be implemented in the model for description of the actual mechanism during precipitation (green). Subsequently, 3. missing parameters and coefficients are determined by evaluation of experimental data (blue).

Finally, 4. model validation is carried out by using PAT to identify measurable process parameters that can be monitored online during operation. These parameters provide also the basis for scale-up to the desired benchmark (black). Estimated time for precipitation runs and analysis are between 1 and 2 weeks.

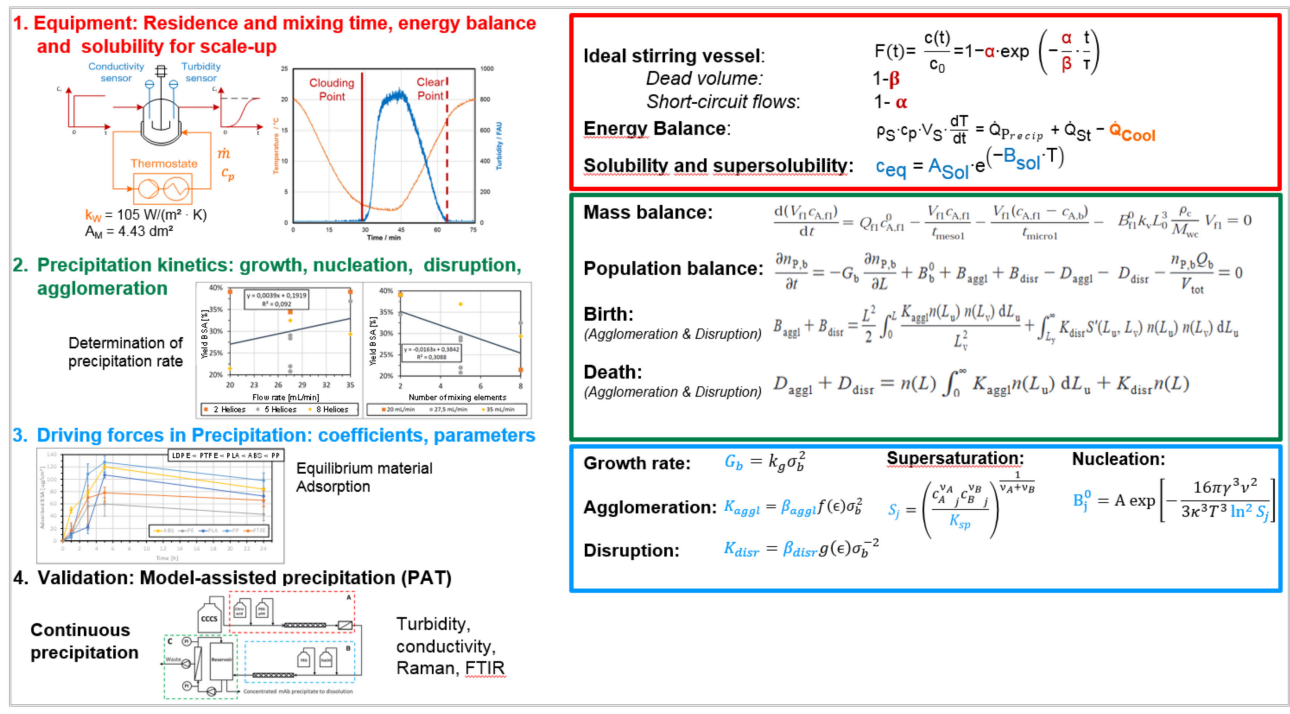

Figure 9. Precipitation process modeling workflow, recipe, SOP.

\subsection{Chromatography, Membrane Adsorption}

Figure 10 summarizes the modeling approach for chromatographic processes. The main equations are the two mass balances for the mobile phase streaming around the particles and the mobile phase inside the pores. For parameter determination, lab-scale experiments can be used as well as mathematical correlations [49,110]. The later are strongly dependent on the separation task, e.g., the size of the molecules. For chromatographic separations of proteins, correlations are known for the axial dispersion-, mass transfer- and diffusion coefficients [44].
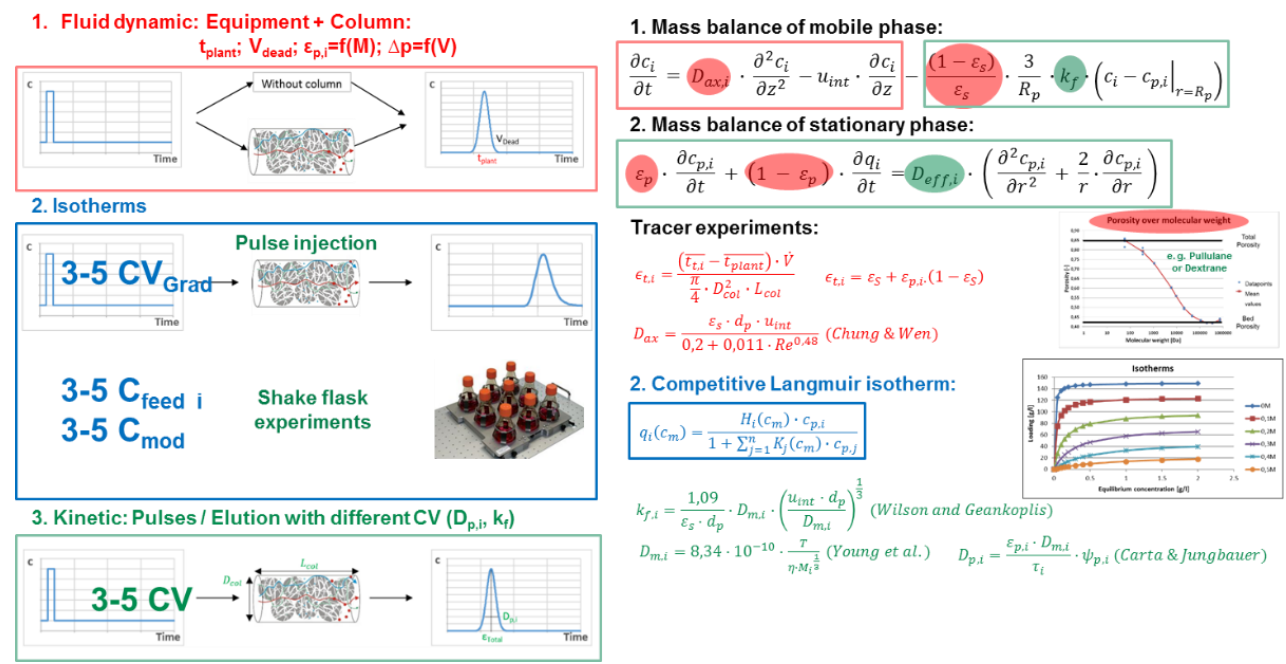

Figure 10. Chromatography process modeling workflow, recipe, SOP.

The order of parameter determination is: 
1. Fluid dynamics (red)

2. Isotherms (blue)

3. Mass transfer and Kinetics (green)

In terms of 1 . fluid dynamics, tracer experiments have to be done. These have to be carried out with polymers of different molecular weight to estimate the voidage, total-as well as pore porosity [111]. The same experiments can be used to calculate the axial dispersion coefficient [112]. Furthermore, it is important to measure the dead volume and mean residence time of the chromatographic equipment/skid in advance.

For 2. isotherm determination, several approaches are known [48,113-115]. The chosen one has to account for different feed concentrations as well as modifier concentrations, if a gradient separation is considered.

To 3. measure the kinetic parameters, pulse injections with different feed concentrations and/or gradient elution varying gradient steepness are performed. Similar experiments can be used for model validation as long as different parameters (concentrations, gradient steepness) are used for parameter determination and validation.

Efforts are 2 days to 1 week with about $1-5 \mathrm{~g}(10-50 \mathrm{~g})$ feed material.

\subsection{Lyophilization}

The model parameter determination concept for lyophilization is shown in Figure 11. Model parameters are not only retrieved experimentally but are also obtained from 0 . substance databases at first. The latter includes functions for water properties at given temperature and pressure. In addition to a prior DSC (Differential Scanning Calorimetry) experiment, performed in order to determine the collapse temperature (IX.: light red), two experiments are needed. The first experiment serves to characterize the equipment and only has to be carried out once per device class. The heat transfer coefficient of the vial (0.3: dark green) as well as the shelf energy balance (0.2: light blue) are calculated. Additionally, the fluid dynamics regarding the chamber pressure (0.1: dark blue) as function of the set pressure of the pump (0.1: dark red) are measured. During the second experiment, the needed temperatures are measured. These are the product temperature as function of height and time (1.1: purple) and the temperature of the chamber during process (1.1: light green). From the mass balance the share of bound water and the desorption coefficient (1.2: yellow) are determined. The properties of the dried material (1.2: pink) are identified after the second experiment.

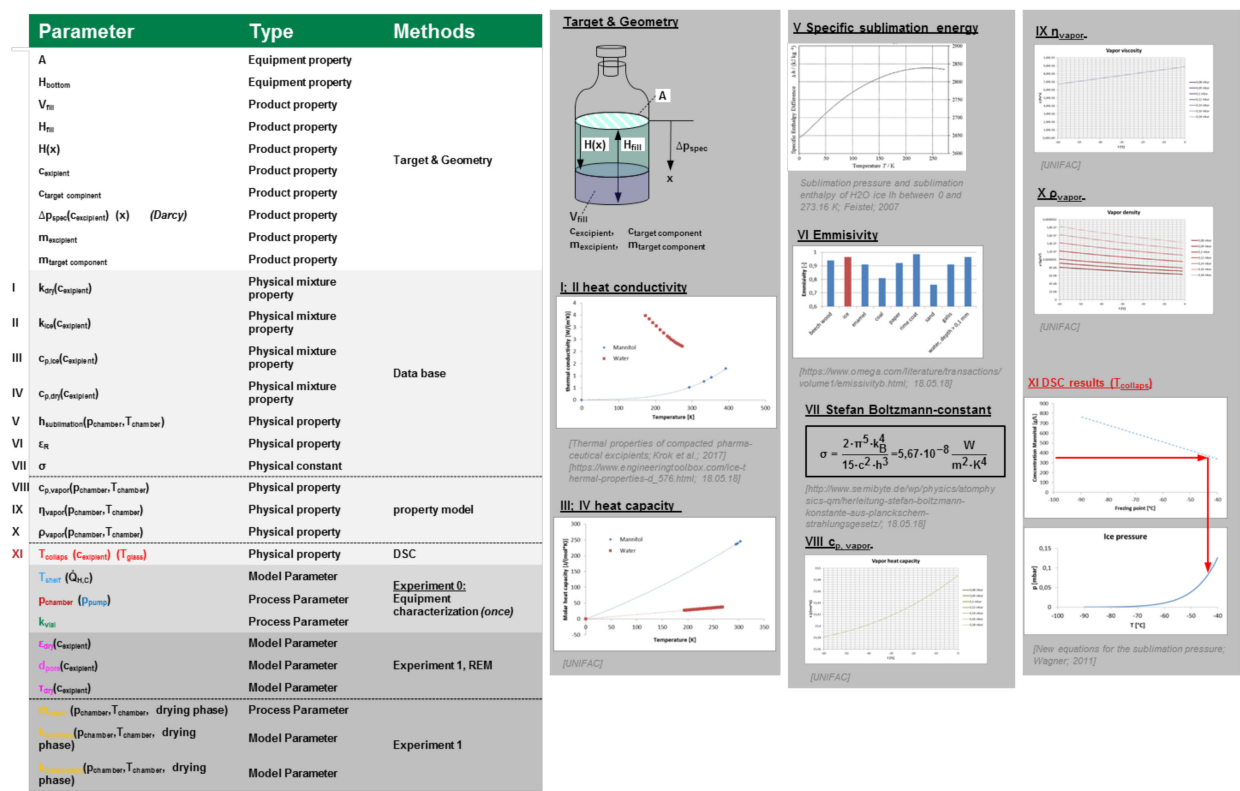

Figure 11. Cont. 


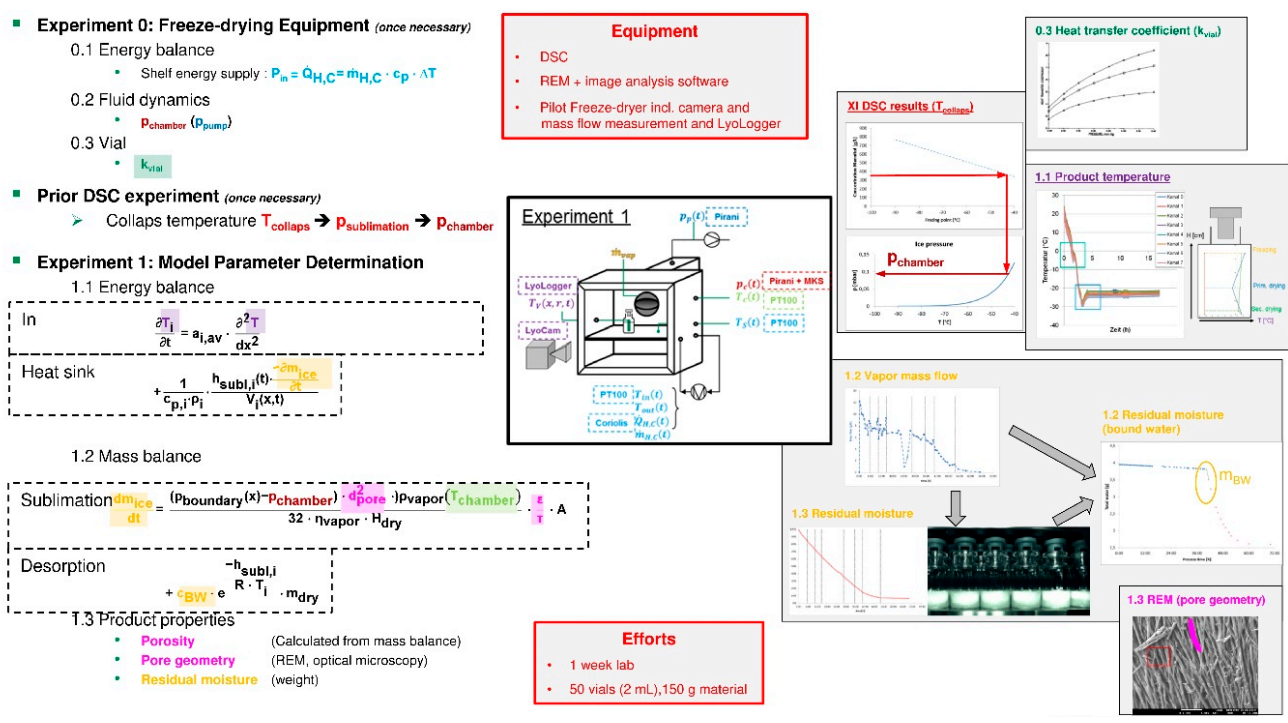

Figure 11. Lyophilization process modeling workflow, recipe, SOP.

Efforts are about 1 week with 50 vial a $2 \mathrm{ml}$ and about $150 \mathrm{~g}$ feed material [116-118].

III. Industrialization

Acceptance and economic benefits are only gained by industrialization, see point IV. case studies.

Recommendation is to start project work in parallel at manufacturing, piloting and process design. The needed change in mindset is highest in process design, therefore with highest efforts, but higher long-term gains.

Figure 12 summarizes the workflow of efficient process development and design allowing more parallel than sequential unit operation design and process integration.

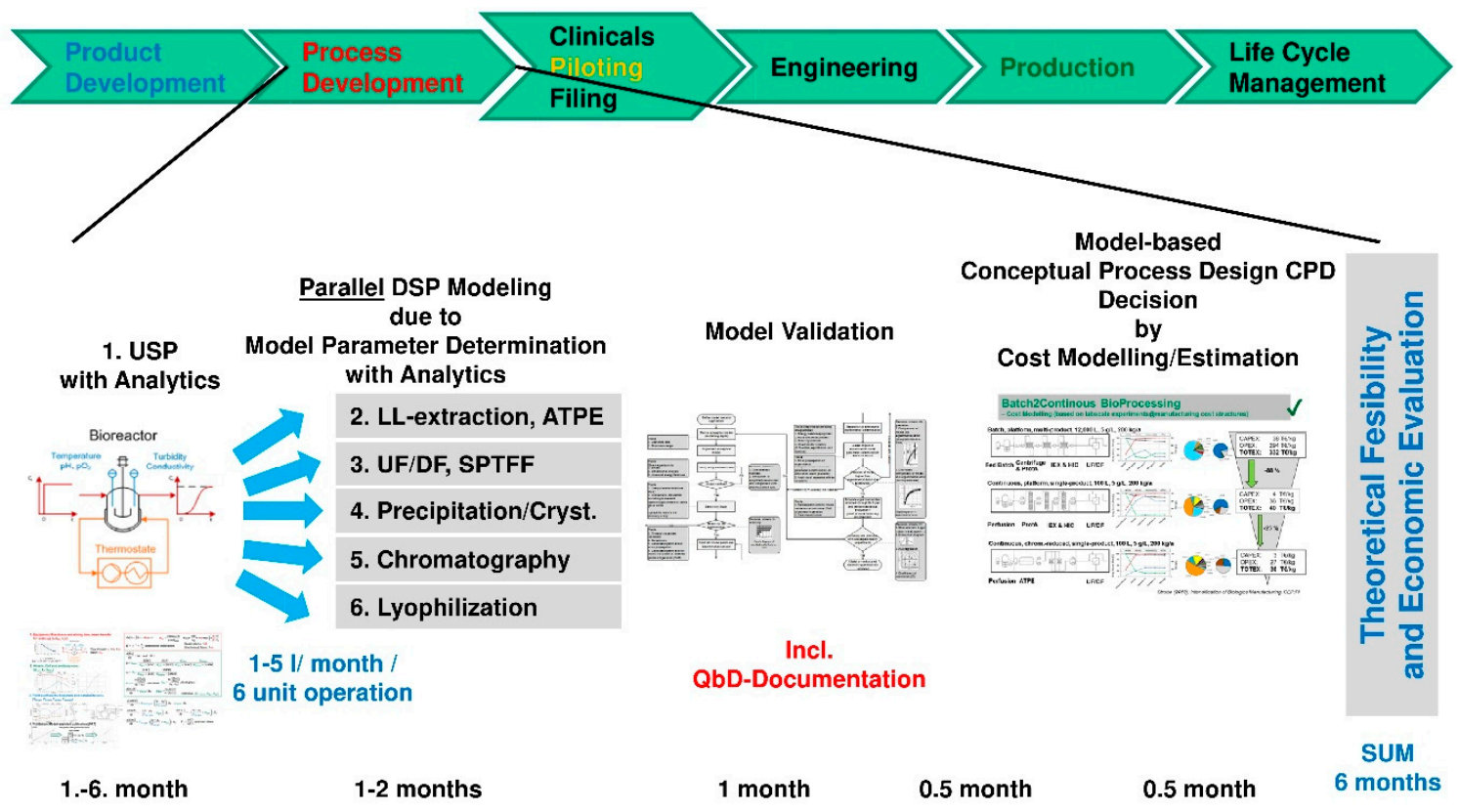

\# PAT development and experimental validation

Figure 12. Efficient process development and design with aid of process modeling.

In the first month of process development and design USP fermentation starts at scales of a few liters. This feedstock is split for the different unit operations applicable to downstream processing such 
as LL-extraction especially ATPE, UF/DF especially SPTFF for continuous operation, precipitation or crystallization as well as all different chromatography units possible and final lyophilization preparing formulation. Each fermentation optimization runs over the process development time span of about 6 months and is fed into the model parameter determination and model validation concept runs of each unit in parallel. Analytics allow to take any relevant component group into account within the models. The separation sequence could be designed in silico a priori by various simulation studies which show the purification power of each step as quantified feed input of the next one. The benefits of appropriate USP and DSP integration have been demonstrated before [12,13,106,119]. Besides, USP modeling with Monod kinetics including reduced metabolomics [52,120-123] enable to integrate USP into total process design as well as lyophilization as the final steps towards formulation [116-118]. The process sequences are evaluated by cost estimation tools added in process modeling easily [86,90]. This results in a theoretical feasibility decision on best process in class. Afterwards, this can be operated in mini- or pilot-scale for model validation towards QbD-documentation and test amount supply. PAT-concepts developed and applied in process development are transferred to be of help in pilotand manufacturing-scale as well. Calibration and maintenance are typical routines, which should be established already during process development. Any sensor drift needs to be counteracted with aid of advanced process control methods. In line release approval is another challenge for regulatory affairs and quality assurance.

\section{Best practice and lessons learned case studies-executive summary}

Best practice and lessons learned are exemplified in case studies cited for further reading along the process engineering workflow:

1. Approach to support manufacturing operation analysis is shown in $[82,83]$

2. Use of cost modeling tools have been demonstrated [86,90]

3. How rigorous process modeling supports manufacturing operation as well as any debottlenecking studies in engineering is e.g., documented in $[50,124]$

4. A distinct workflow is recommended for quantitative model validation in [94]

5. After about 25 years in process modeling in combination with experimental model parameter determination concepts in laboratory scale the working group exemplified total process studies in pilot scale such as [48,53,125-133]

6. The successful application of the QbD-approach in combination with PAT-tools is published [53, 119,133-141]

7. Integration of PAT-tools for advanced process control studies are linked to $[52,53,106,132,133,139,140]$

Figure 13 shows the mini-plant concept for model validation and piloting with inline process control (IPC) and PCS integrated. All unit operations described before are included and total process operation is feasible in batch or continuous mode.

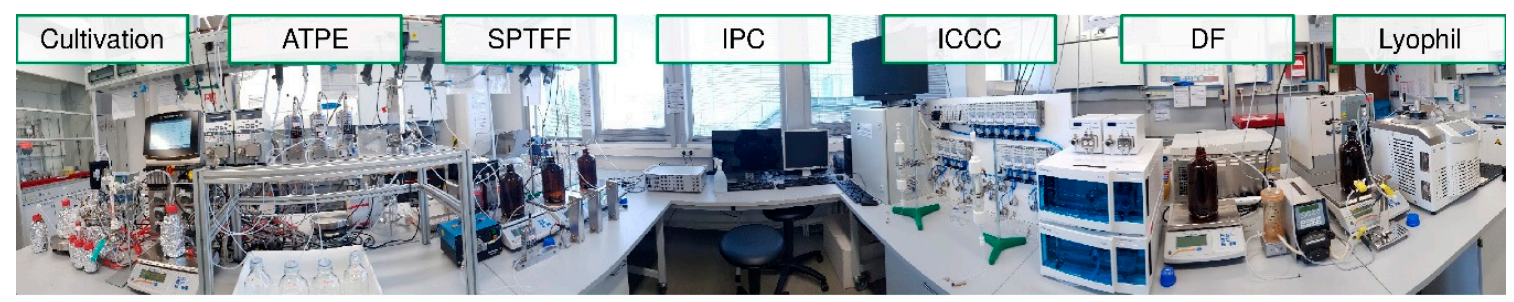

Figure 13. Mini-plant for model validation and piloting at the institute.

\section{Summary}

Digitalization does not generate added value, but creates shifts towards new business models. As an example, not hardware-based products, but software-like services are sold [142,143] e.g., not drugs, but services for health care. As a basic rule the highest value is gained directly at the 
end user, i.e., customer. Engineering art and manufacturing is (tried to be) pushed into the back row by merchandizing internet platforms with direct and permanent access to the end customers, in case those services are not included or offered by the manufacturers themselves (or by their unions and associations). Coopetition (Coinage: Cooperation or Competition) may be another approach. Nevertheless, basic pre-condition is competitive manufacturing technology based on best-in-class processes.

To anticipate molecular variety of novel drug formats requires fast and efficient process development and design as well as efficient piloting for regulatory approval and industrialization in manufacturing scale. Key-enabling technology adopted from chemical engineering and transferred into biotechnology is rigorous, i.e., physical-chemical based predictive process modeling with combined experimental model parameter determination miniaturized in laboratory scale.

Definitions of modeling approaches to accelerate biomanufacturing are provided and analyzed.

The state-of-the-art of all unit operations available for total process design and a quantitative distinct approach for model validation is described in this paper, as these are the central points for industrial acceptance. In addition, an efficient experimental model parameter determination workflow with standardized laboratory scale equipment is available, reducing necessary time to about 2-3 weeks for all unit operations in parallel, which enables to realize again total process development times of 6 months for individual novel drug molecules-such as today with mAbs utilizing platform-processes. Therefore, in a way, process design with the aid of process modeling in combination with experimental model parameter determination in laboratory scale could be summarized as the central platform method/technology for future biotherapeutic molecules.

Further in depth literature is referred to, in order to give a more detailed insight to overcome common prejudices by data driven decisions besides this overview.

To conclude, case studies and lessons learned are listed to derive recommendations for in-company structuring of interdisciplinary teams towards efficient implementation of these approaches for the new approach to biomanufacturing. Different options are discussed and evaluated, concluding that the starting points and necessary steps for companies towards fast industrialization of new classes of biotherapeutics are available and only need to be applied.

Innovation is not only needed in drug discovery but as well in manufacturing technology methodologies, i.e., engineering. Engineering science in pharmaceutical industries is too often reduced to detail engineering, procurement and maintenance of equipment missing the sound methodological skills needed in process development and design with the aid of modern methods: Societal needs for innovative, yet affordable medicines within health care systems are only covered, when any drug candidate of use can be economically and sustainable manufactured in the required scales.

Industrial projects experience over the last three decades proved some crucial recommendations of tasks and objectives for industrial project organization, team education and training, strategic project management, and availability of useful tools, which are in summary vital for efficient industrialization success.

The described approach is universal and applicable for any biomolecule. Total process modeling is achieved by combining each unit operation model in any process flowsheet sequence of interest for any model parameter set determined experimentally in laboratory scale, as described.

The approach will be exemplified in detail within the special issue by at least one article for each unit operation in detail and by case studies.

Author Contributions: This is a joint work of all authors, nevertheless each author was especially in charge of his/her expert topic: S.Z.-R. and F.M. for chromatography and membrane adsorption, A.S. for liquid liquid extraction, M.M. for process control, L.U. for process analytical technology, M.H. for membrane processes and crystallization, M.K. and L.L. for upstream fermentation. R.D. reviewed the industrial state of the art and needs and J.S. acts as the main supervisor.

Funding: This research received funding from BMWi project "Traceless Plant Traceless Production". 
Acknowledgments: The authors would like to acknowledge their institute's laboratory colleagues, especially Frank Steinhäuser and Volker Strohmeyer as well as the PCS team Thomas Knebel with Christian Siemers, Automation Technology at Clausthal University of Technology. In addition, the authors would like to thank BMWI, especially Gahr, for project funding "Traceless Plant Traceless Production" and the whole TPTP consortium. Moreover, Reinhard Ditz, formerly with Merck KGaA/Darmstadt, is acknowledged for his input and ideas as well as all other lecturers of the education and trainings courses on Downstream Processing, Continuous Biomanufacturing, Phytoextraction and Process Chromatography of FAH (Forschungsvereinigung der Arzneimittelhersteller e.V.) Bonn and PDA (Parenteral Drug Association) organization Berlin.

Conflicts of Interest: The authors declare no conflict of interest.

\section{Abbreviations}

$\begin{array}{ll}\text { AI } & \text { artificial intelligence } \\ \text { APC } & \text { advanced process control } \\ \text { ATF } & \text { alternating tangential flow filtration } \\ \text { ATPE } & \text { aqueous two-phase extraction } \\ \text { ATR } & \text { Attenuated total reflectance } \\ \text { Dax }_{\text {DF }} & \text { axial dispersion coefficient } \\ \text { DoE } & \text { diafiltration } \\ \text { DSC } & \text { design of experiments } \\ \text { DSP } & \text { downstream processing } \\ \text { EMA } & \text { European Medicines Agency } \\ \text { FDA } & \text { Food and Drug administration } \\ \text { FTIR } & \text { Fourier-transformed infrared spectroscopy } \\ \text { HIC } & \text { hydrophobic interaction chromatography } \\ \text { iCCC } & \text { integrated counter-current chromatography } \\ \text { IEX } & \text { ion exchange chromatography } \\ \text { IOT } & \text { internet of things } \\ \text { IPC } & \text { inline process control analytics } \\ \text { keff } & \text { effective mass transfer coefficient } \\ \text { LLE } & \text { liquid-liquid extraction } \\ \text { mAb } & \text { monoclonal antibody } \\ \text { MCSGP } & \text { multicolumn countercurrent solvent gradient purification } \\ \text { MPC } & \text { model-based process control } \\ \text { MRSA } & \text { methicilline-resistent Staphylococcus aureus } \\ \text { MS } & \text { mass spectrometry } \\ \text { NN } & \text { neuronal networks } \\ \text { OQ } & \text { Operation qualification } \\ \text { PAT } & \text { process analytical technology } \\ \text { PCA } & \text { principle component analysis } \\ \text { PCS } & \text { process control system } \\ \text { Prot A } & \text { protein A chromatography } \\ \text { QA } & \text { quality assurance } \\ \text { QbD } & \text { quality-by-design } \\ \text { SOP } & \text { standard operation procedure } \\ \text { SPTFF } & \text { single-pass tangential flow filtration } \\ \text { UF } & \text { ultrafiltration } \\ \text { USP } & \text { upstream processing } \\ \text { VLP } & \text { virus-like particles } \\ & \end{array}$




\section{References}

1. Shukla, A.A.; Thömmes, J. Recent advances in large-scale production of monoclonal antibodies and related proteins. Trends Biotechnol. 2010, 28, 253-261. [CrossRef] [PubMed]

2. Jain, E.; Kumar, A. Upstream processes in antibody production: evaluation of critical parameters. Biotechnol. Adv. 2008, 26, 46-72. [CrossRef] [PubMed]

3. Gagnon, P. Technology trends in antibody purification. J. Chromatogr. A 2012, 1221, 57-70. [CrossRef] [PubMed]

4. Elvin, J.G.; Couston, R.G.; van der Walle, C.F. Therapeutic antibodies: market considerations, disease targets and bioprocessing. Int. J. Pharm. 2013, 440, 83-98. [CrossRef] [PubMed]

5. Li, F.; Vijayasankaran, N.; Shen, A.; Kiss, R.; Amanullah, A. Cell culture processes for monoclonal antibody production. $m A$ bs 2010, 2, 466-477. [CrossRef] [PubMed]

6. Gronemeyer, P.; Ditz, R.; Strube, J. Trends in Upstream and Downstream Process Development for Antibody Manufacturing. Bioengineering 2014, 1, 188-212. [CrossRef]

7. Subramanian, G. (Ed.) Continuous Processing in Pharmaceutical Manufacturing; WILEY-VCH: Weinheim, Germany, 2015.

8. Liu, H.F.; Ma, J.; Winter, C.; Bayer, R. Recovery and purification process development for monoclonal antibody production. $m A$ bs 2010, 2, 480-499. [CrossRef] [PubMed]

9. Birch, J.R.; Racher, A.J. Antibody production. Adv. Drug Delivery Rev. 2006, 58, 671-685. [CrossRef]

10. Thiess, H.; Zobel-Roos, S.; Gronemeyer, P.; Ditz, R.; Strube, J. Engineering Challenges of Continuous Biomanufacturing Processes (CBP). In Continuous Biomanufacturing: Innovative Technologies and Methods; Subramanian, G., Ed.; WILEY-VCH: Weinheim, Germany, 2017; pp. 69-107.

11. Zobel-Roos, S.; Thiess, H.; Gronemeyer, P.; Ditz, R.; Strube, J. Continuous Chromatography as a Fully Integrated Process in Continuous Biomanufacturing. In Continuous Biomanufacturing: Innovative Technologies and Methods; Subramanian, G., Ed.; WILEY-VCH: Weinheim, Germany, 2017; pp. 369-393.

12. Gronemeyer, P.; Thiess, H.; Zobel-Roos, S.; Ditz, R.; Strube, J. Integration of Upstream and Downstream in Continuous Biomanufacturing. In Continuous Biomanufacturing: Innovative Technologies and Methods; Subramanian, G., Ed.; WILEY-VCH: Weinheim, Germany, 2017; pp. 481-510.

13. Strube, J.; Ditz, R.; Kornecki, M.; Huter, M.; Schmidt, A.; Thiess, H.; Zobel-Roos, S. Process Intensification in Biologics Manufacturing. Chem. Eng. Process. 2018, 133, 278-293. [CrossRef]

14. Hanna, E.; Rémuzat, C.; Auquier, P.; Toumi, M. Advanced therapy medicinal products: current and future perspectives. J. Mark. Access Health Policy 2016, 4, 31036. [CrossRef]

15. Martins, J.P.; Santos, J.M.; de Almeida, J.M.; Filipe, M.A.; de Almeida, M.V.T.; Almeida, S.C.P.; Água-Doce, A.; Varela, A.; Gilljam, M.; Stellan, B.; et al. Towards an advanced therapy medicinal product based on mesenchymal stromal cells isolated from the umbilical cord tissue: Quality and safety data. Stem Cell Res. Ther. 2014, 5, 9. [CrossRef] [PubMed]

16. Ramqvist, T.; Andreasson, K.; Dalianis, T. Vaccination, immune and gene therapy based on virus-like particles against viral infections and cancer. Expert Opin. Biol. Ther. 2007, 7, 997-1007. [CrossRef] [PubMed]

17. Warnock, J.N.; Merten, O.-W.; Al-Rubeai, M. Cell culture processes for the production of viral vectors for gene therapy purposes. Cytotechnology 2006, 50, 141-162. [CrossRef] [PubMed]

18. Fuenmayor, J.; Gòdia, F.; Cervera, L. Production of virus-like particles for vaccines. New Biotechnol. 2017, 39, 174-180. [CrossRef] [PubMed]

19. Kushnir, N.; Streatfield, S.J.; Yusibov, V. Virus-like particles as a highly efficient vaccine platform: Diversity of targets and production systems and advances in clinical development. Vaccine 2012, 31, 58-83. [CrossRef]

20. Roldão, A.; Mellado, M.C.M.; Castilho, L.R.; Carrondo, M.J.T.; Alves, P.M. Virus-like particles in vaccine development. Expert Rev. Vaccines 2010, 9, 1149-1176. [CrossRef]

21. Vicente, T.; Roldão, A.; Peixoto, C.; Carrondo, M.J.T.; Alves, P.M. Large-scale production and purification of VLP-based vaccines. J. Invertebr. Pathol. 2011, 107, S42-S48. [CrossRef]

22. Cho, B.S.; Kim, J.O.; Ha, D.H.; Yi, Y.W. Exosomes derived from human adipose tissue-derived mesenchymal stem cells alleviate atopic dermatitis. Stem Cell Res. Ther. 2018, 9, 187. [CrossRef]

23. Ha, D.; Yang, N.; Nadithe, V. Exosomes as therapeutic drug carriers and delivery vehicles across biological membranes: Current perspectives and future challenges. Acta Pharm. Sin. B 2016, 6, 287-296. [CrossRef] 
24. Keller, S.; Sanderson, M.P.; Stoeck, A.; Altevogt, P. Exosomes: From biogenesis and secretion to biological function. Immunol. Lett. 2006, 107, 102-108. [CrossRef]

25. Watson, D.C.; Bayik, D.; Srivatsan, A.; Bergamaschi, C.; Valentin, A.; Niu, G.; Bear, J.; Monninger, M.; Sun, M.; Morales-Kastresana, A.; et al. Efficient production and enhanced tumor delivery of engineered extracellular vesicles. Biomaterials 2016, 105, 195-205. [CrossRef] [PubMed]

26. ICH. Quality Risk Management Q9, 2005 (Step 4 Version). Available online: https://www.ich.org/ fileadmin/Public_Web_Site/ICH_Products/Guidelines/Quality/Q9/Step4/Q9_Guideline.pdf (accessed on 17 January 2018).

27. ICH. Pharmaceutical Quality System Q10, 2008 (Step 4 Version). Available online: http:/ / www.ich.org/ fileadmin/Public_Web_Site/ICH_Products/Guidelines/Quality/Q10/Step4/Q10_Guideline.pdf (accessed on 17 January 2018).

28. ICH. Pharmaceutical Development Q8 (R2), 2009 (Step 4 Version). Available online: https:/ / www.ich.org/ fileadmin/Public_Web_Site/ICH_Products / Guidelines/Quality/Q8_R1/Step4/Q8_R2_Guideline.pdf (accessed on 2 January 2015).

29. ICH. Development and Manufacturing of Drug Substances Q11, 2013 (Step 4 Version). Available online: http://www.ich.org/fileadmin/Public_Web_Site/ICH_Products/Guidelines/Quality/Q11/Q11_ Step_4.pdf (accessed on 17 January 2018).

30. Express-scripts.com. The Need for U.S. Biosimilars. Available online: http://lab.express-scripts.com/ lab/insights/drug-options/ \{\}/link.aspx?_id=905e58d6e6494fb4ae1b2581566b3538\&_z=z (accessed on 17 November 2018).

31. PharmTech. Biosimilars and Follow-on-Biologics Market to Hit \$35 Billion Globally by 2020. Available online: http:/ / www.pharmtech.com/biosimilars-and-follow-biologics-market-hit-35-billion-globally-2020 (accessed on 3 November 2018).

32. Epstein, M.S.; Ehrenpreis, E.D.; Kulkarni, P.M. Biosimilars: The need, the challenge, the future: The FDA perspective. Am. J. Gastroenterol. 2014, 109, 1856-1859. [CrossRef]

33. JSR Life Sciences. Chromassette. Available online: https://www.jsrlifesciences.com/bioprocess/ chromassette (accessed on 6 November 2018).

34. Subramanian, G. (Ed.) Continuous Biomanufacturing. In Innovative Technologies and Methods; WILEY-VCH: Weinheim, Germany, 2017.

35. Schofield, M. Current state of the art in continuous bioprocessing. Biotechnol. Lett. 2018. [CrossRef] [PubMed]

36. Bisschops, M.; Schofield, M.; Grace, J. Two Mutually Enabling Trends: Continuous Bioprocessing and SingleUse Technologies. In Continuous Biomanufacturing: Innovative Technologies and Methods; Subramanian, G., Ed.; WILEY-VCH: Weinheim, Germany, 2017; pp. 149-170.

37. Clutterbuck, A.; Beckett, P.; Lorenzi, R.; Sengler, F.; Bisschop, T.; Haas, J. Single-Pass Tangential Flow Filtration (SPTFF) in Continuous Biomanufacturing. In Continuous Biomanufacturing: Innovative Technologies and Methods; Subramanian, G., Ed.; WILEY-VCH: Weinheim, Germany, 2017; pp. 423-456.

38. Pollock, J.; Coffman, J.; Ho, S.V.; Farid, S.S. Integrated continuous bioprocessing: Economic, operational, and environmental feasibility for clinical and commercial antibody manufacture. Biotechnol. Prog. 2017, 33, 854-866. [CrossRef] [PubMed]

39. Karst, D.J.; Steinebach, F.; Morbidelli, M. Continuous integrated manufacturing of therapeutic proteins. Curr. Opin. Biotechnol. 2018, 53, 76-84. [CrossRef] [PubMed]

40. Bioprozesstechnik; Chmiel, H. (Eds.) 3., neu bearb. Aufl.; Spektrum Akademischer Verlag: Heidelberg, Germany, 2011.

41. Ladisch, M.R. Bioprocess Engineering (Biotechnology). In Van Nostrand's Scientific Encyclopedia; John Wiley \& Sons, Inc.: New York, NY, USA, 2005.

42. Ben Yahia, B.; Malphettes, L.; Heinzle, E. Macroscopic modeling of mammalian cell growth and metabolism. Appl. Microbiol. Biotechnol. 2015, 99, 7009-7024. [CrossRef] [PubMed]

43. Schuler, H. Prozessimulation; WILEY-VCH: Weinheim, Germany, 1995.

44. Carta, G.; Jungbauer, A. Protein Chromatography. Process Development and Scale-Up; WILEY-VCH: Weinheim, Germany, 2010.

45. Strube, J. Prädiktive Modellierung von Trennverfahren. Chem. Ing. Tech. 2012, 84, 867. [CrossRef]

46. Kroll, P.; Hofer, A.; Ulonska, S.; Kager, J.; Herwig, C. Model-Based Methods in the Biopharmaceutical Process Lifecycle. Pharm. Res. 2017, 34, 2596-2613. [CrossRef] 
47. Nfor, B.K.; Verhaert, P.D.E.M.; van der Wielen, L.A.M.; Hubbuch, J.; Ottens, M. Rational and systematic protein purification process development: The next generation. Trends Biotechnol. 2009, 27, 673-679. [CrossRef]

48. Zobel-Roos, S. Entwicklung, Modellierung und Validierung von Integrierten Kontinuierlichen GegenstromChromatographie-Prozessen, 1. Auflage; Shaker: Herzogenrath, Germany, 2018.

49. Strube, J. Technische Chromatographie: Auslegung, Optimierung, Betrieb und Wirtschaftlichkeit; Shaker: Aachen, Germany, 2000.

50. Wiesel, A.; Schmidt-Traub, H.; Lenz, J.; Strube, J. Modelling gradient elution of bioactive multicomponent systems in non-linear ion-exchange chromatography. J. Chromatogr. A 2003, 1006, 101-120. [CrossRef]

51. Thiess, H.; Leuthold, M.; Grummert, U.; Strube, J. Module design for ultrafiltration in biotechnology: Hydraulic analysis and statistical modeling. J. Membr. Sci. 2017, 540, 440-453. [CrossRef]

52. Kornecki, M.; Strube, J. Process Analytical Technology for Advanced Process Control in Biologics Manufacturing with the Aid of Macroscopic Kinetic Modeling. Bioengineering 2018, 5, 25. [CrossRef] [PubMed]

53. Schmidt, A.; Richter, M.; Rudolph, F.; Strube, J. Integration of Aqueous Two-Phase Extraction as Cell Harvest and Capture Operation in the Manufacturing Process of Monoclonal Antibodies. Antibodies 2017, 6, 21. [CrossRef]

54. Thiess, H.; Schmidt, A.; Strube, J. Development of a Scale-up Tool for Pervaporation Processes. Membranes 2018, 8, 4. [CrossRef] [PubMed]

55. Bayer. Open Systems Pharmacology Suite with PK-Sim and MoBi: Unmatched Flexibility-Unlimited Transparency. Available online: http:/ / www.systems-biology.com/products/pk-sim.html (accessed on 2 November 2018).

56. Meyer, E.F.; Swanson, S.M.; Williams, J.A. Molecular modelling and drug design. Pharmacol. Ther. 2000, 85, 113-121. [CrossRef]

57. Duch, W.; Swaminathan, K.; Meller, J. Artificial Intelligence Approaches for Rational Drug Design and Discovery. CPD 2007, 13, 1497-1508. [CrossRef]

58. Minsky, M. Matter, Mind and Models. In Proceedings of the IFIP Congress, New York, NY, USA, 24-29 May 1965; pp. 45-49.

59. Guidance for Industry—Sterile Drug Products Produced by Aseptic Processing-Current Good Manufacturing Practice; FDA: Silver Spring, MD, USA, 2004.

60. Guidance for Industry CMC Postapproval Manufacturing Changes to Be Documented in Annual Reports; FDA: Silver Spring, MD, USA, 2014.

61. Guidance for Industry Changes to an Approved NDA or ANDA; FDA: Silver Spring, MD, USA, 2004.

62. Boschert, S.; Rosen, R. 5. Digital Twin-The Simulation Aspect. In Mechatronic Futures; Hehenberger, P., Bradley, D., Eds.; Springer International Publishing: Cham, Switzerland, 2016.

63. Rosen, R.; von Wichert, G.; Lo, G.; Bettenhausen, K.D. About the Importance of Autonomy and Digital Twins for the Future of Manufacturing. Ifac-Pap. 2015, 48, 567-572. [CrossRef]

64. Eigner, M.; Koch, W.; Muggeo, C. Modellbasierter Entwicklungsprozess Cybertronischer Systeme; Springer Berlin Heidelberg: Berlin/Heidelberg, Germany, 2017.

65. Brown, J. Siemens Digital Twin Strategy. Available online: https://tech-clarity.com/siemens-plm-twin/7017 (accessed on 3 November 2018).

66. Galvanauskas, V.; Simutis, R.; Lübbert, A. Hybrid process models for process optimisation, monitoring and control. Bioprocess Biosyst. Eng. 2004, 26, 393-400. [CrossRef]

67. Ji, Y. Model Based Process Design for Bioprocess Optimisation: Case Studies on Precipitation with Its Applications in Antibody Purification; University College London: London, UK, 2012.

68. McCullagh, P. What is a statistical model? Ann. Stat. 2002, 30, 1225-1310. [CrossRef]

69. Dreyfus, H.L. What Computers Can't Do. The Limits of Artificial Intelligence; Harper \& Row: New York, NY, USA, 1979.

70. Domingos, P. The Master Algorithm. How the Quest for the Ultimate Learning Machine Will Remake Our World, First Paperback ed.; Basic Books: New York, NY, USA, 2018.

71. Nielsen, H.; Brunak, S.; von Heijne, G. Machine learning approaches for the prediction of signal peptides and other protein sorting signals. Protein Eng. Des. Sel. 1999, 12, 3-9. [CrossRef] 
72. CNN. AI Set to Exceed Human Brain Power. Available online: http:/ / edition.cnn.com/2006/TECH/science/ 07/24/ai.bostrom/ (accessed on 3 November 2018).

73. Dreyfus, H.L. What Computers Still Can't Do. A Critique of Artificial Reason; 6th print; MIT Press: Cambridge, MA, USA, 1999.

74. Bostrom, N. Superintelligence. Paths, Dangers, Strategies, 1st ed.; Oxford University Press: Oxford, UK, 2014.

75. Charaniya, S.; Hu, W.-S.; Karypis, G. Mining bioprocess data: Opportunities and challenges. Trends Biotechnol. 2008, 26, 690-699. [CrossRef] [PubMed]

76. Burghaus, R.; Leineweber, D.; Lippert, J. Einsatz von Data-Mining zur Analyse eines Polymerprozesses. Chem. Ing. Tech. 2003, 75, 897-900. [CrossRef]

77. Balakin, K.V. Pharmaceutical Data Mining. Approaches and Applications for Drug Discovery; Wiley: Hoboken, NJ, USA, 2010.

78. Müller, F.-J.; Schuppert, A. Few inputs can reprogram biological networks. Nature 2011, 478, E4. [CrossRef]

79. Wolkenhauer, O.; Auffray, C.; Brass, O.; Clairambault, J.; Deutsch, A.; Drasdo, D.; Gervasio, F.; Preziosi, L.; Maini, P.; Marciniak-Czochra, A.; et al. Enabling multiscale modeling in systems medicine. Genome Med. 2014, 6, 21. [CrossRef] [PubMed]

80. Kuepfer, L.; Schuppert, A. Systems Medicine in Pharmaceutical Research and Development. In Systems Medicine, 1st ed.; Schmitz, U., Wolkenhauer, O., Eds.; Humana Press: New York, NY, USA, 2016; pp. 87-104.

81. Schuppert, A. Data Mining. Bayer Res. Mag. 2000, 16.

82. Helling, C.; Strube, J. Modeling and Experimental Model Parameter Determination with Quality by Design for Bioprocesses. In Biopharmaceutical Production Technology, 1. Aufl.; Subramanian, G., Ed.; WILEY-VCH: Weinheim, Germany, 2012; pp. 409-443.

83. Helling, C.; Dams, T.; Gerwat, B.; Belousov, A.; Strube, J. Physical characterization of column chromatography: Stringent control over equipment performance in biopharmaceutical production. Trends Chromatogr. 2013, 2013, 55-71.

84. Strube, J.; Zobel-Roos, S. ITVP Training Course; DSP. Purification of Biomolecules: Clausthal-Zellerfeld, Germany, 2016.

85. Strube, J.; Ditz, R. ITVP Training Course; Process Chromatography: Clausthal-Zellerfeld, Germany.

86. Sommerfeld, S.; Strube, J. Challenges in biotechnology production-Generic processes and process optimization for monoclonal antibodies. Chem. Eng. Process. Process Intensif. 2005, 44, 1123-1137. [CrossRef]

87. Jenkins, M.J.; Farid, S.S. Cost-effective bioprocess design for the manufacture of allogeneic CAR-T cell therapies using a decisional tool with multi-attribute decision-making analysis. Biochem. Eng. J. 2018, 137, 192-204. [CrossRef]

88. Pereira Chilima, T.D.; Moncaubeig, F.; Farid, S.S. Impact of allogeneic stem cell manufacturing decisions on cost of goods, process robustness and reimbursement. Biochem. Eng. J. 2018, 137, 132-151. [CrossRef]

89. Toumi, A.; Jürgens, C.; Jungo, C.; Maier, B.A.; Papavasileioum, V.; Petrides, D.P. Design and Optimization of a Large Scale Biopharmaceutical Facility Using Process Simulation and Scheduling Tools. Pharm. Eng. 2010, 30, 1-9.

90. Strube, J.; Sommerfeld, S.; Lohrmann, M. Processes Development and Optimization for Biotechnology Production-Monoclonal Antibodies. In Bioseparation and Bioprocessing: A Handbook, 2.; Subramanian, G., Ed.; WILEY-VCH: Weinheim, Germany; New-York, NY, USA, 2007; pp. 65-99.

91. Green, D.W.; Perry, R.H. (Eds.) Perry's Chemical Engineers' Handbook, 8th ed.; McGraw-Hill: New York, NY, USA, 2008.

92. Peters, M.S.; Timmerhaus, K.D.; West, R.E. Plant Design and Economics for Chemical Engineers, 5th ed.; McGraw-Hill: Boston, MA, USA, 2003.

93. Netzer, F. Digitale Transformation bei BASF-Fallstricke und Erfolgsbeispiele aus der Umsetzungspraxis. Chem. Ing. Tech. 2018, 90, 1293-1294. [CrossRef]

94. Sixt, M.; Uhlenbrock, L.; Strube, J. Toward a Distinct and Quantitative Validation Method for Predictive Process Modelling-On the Example of Solid-Liquid Extraction Processes of Complex Plant Extracts. Processes 2018, 6, 66. [CrossRef]

95. Sargent, R.G. Verification and Validation of Simulation Models. In Proceedings of the 2011 Winter Simulation Conference: (WSC), Phoenix, AZ, USA, 11-14 December 2011, Including the MASM (Modeling and Analysis for Semiconductor Manufacturing) Conference; Jain, S., Ed.; IEEE: Piscataway, NJ, USA, 2011; pp. 183-198. 
96. Schleisinger, S.; Crosbie, R.E.; Gagné, R.E. Terminology for model credibility. Simulation 1979, 32, $103-104$. [CrossRef]

97. Pharmaceutical Technology. Samsung BioLogics' Third Manufacturing Facility, Songdo. Available online: https: / / www.pharmaceutical-technology.com/projects/samsung-biologics-third-manufacturingfacility-songdo/ (accessed on 17 November 2018).

98. Strube, J.; Zobel-Roos, S.; Ditz, R. Chapter X: Process Chromatography. In Ullmann's Encyclopedia of Industrial Chemistry; Wiley: Chichester, UK, 2019.

99. GE Healthcare. Available online: https://www.gehealthcare.com/ (accessed on 3 November 2018).

100. Bio Rad. Available online: http:/ / www.bio-rad.com/ (accessed on 3 November 2018).

101. Pall Corporation. Available online: https:/ / www.pall.com/ (accessed on 3 November 2018).

102. Merck Millipore. Available online: http:/ /www.merckmillipore.com (accessed on 3 November 2018).

103. Kornecki, M.; Strube, J. Process analytical technology mechanisms in biologics manufacturing. Chem. Ing. Tech. 2018, 90, 1270. [CrossRef]

104. Kornecki, M. Host Cell Proteins in Biologics Manufacturing. A Methodical and Systematic Integration of Upstream and Downstream Processing; Achema: Frankfurt am Main, Germany, 2018.

105. Kornecki, M. Process Analytical Technology Mechanisms in Biologics Manufacturing; Achema: Frankfurt am Main, Germany, 2018.

106. Kornecki, M.; Mestmäcker, F.; Zobel-Roos, S.; Heikaus de Figueiredo, L.; Schlüter, H.; Strube, J. Host Cell Proteins in Biologics Manufacturing: The Good, the Bad, and the Ugly. Antibodies 2017, 6, 13. [CrossRef]

107. Huter, M.; Strube, J. Model-Based Optimization of SPTFF Ultrafiltration for Integration in Continuous Biopharmaceutical Processing. Chem. Ing. Tech. 2018, 90, 1251. [CrossRef]

108. Huter, M. Modeling of Continuous Ultrafiltration for Biopharmaceutical Processes; Achema: Frankfurt am Main, Germany, 2018.

109. Lucke, M.; Koudous, I.; Sixt, M.; Huter, M.J.; Strube, J. Integrating crystallization with experimental model parameter determination and modeling into conceptual process design for the purification of complex feed mixtures. Chem. Eng. Res. Des. 2018, 133, 264-280. [CrossRef]

110. Altenhöner, U.; Meurer, M.; Strube, J.; Schmidt-Traub, H. Parameter estimation for the simulation of liquid chromatography. J. Chromatogr. A 1997, 769, 59-69. [CrossRef]

111. Rouquerol, J.; Baron, G.V.; Denoyel, R.; Giesche, H.; Groen, J.; Klobes, P.; Levitz, P.; Neimark, A.V.; Rigby, S.; Skudas, R.; et al. The characterization of macroporous solids: An overview of the methodology. Microporous Mesoporous Mater. 2012, 154, 2-6. [CrossRef]

112. Levenspiel, O. Chemical Reaction Engineering, 3rd ed.; Wiley: New York, NY, USA, 1999.

113. Seidel-Morgenstern, A. Experimental determination of single solute and competitive adsorption isotherms. J. Chromatogr. A 2004, 1037, 255-272. [CrossRef]

114. Mazzotti, M. Equilibrium theory based design of simulated moving bed processes for a generalized Langmuir isotherm. J. Chromatogr. A 2006, 1126, 311-322. [CrossRef] [PubMed]

115. Guiochon, G.; Felinger, A.; Shirazi, D.G.; Katti, A.M. Fundamentals of Preparative and Nonlinear Chromatography, 2th ed.; Elsevier Academic Press: Amsterdam, The Netherlands, 2006.

116. Klepzig, L.; Strube, J. Rigorous modeling of lyophilization for botanicals and biologics process integration. Chem. Ing. Tech. 2018, 90, 1299. [CrossRef]

117. Klepzig, L. Rigorous Modelling of Lyophilisation for Botanicals and Biologics Process Integration; Achema: Frankfurt am Main, Germany, 2018.

118. Klepzig, L. Process Modelling in Combination with Experimental Model Parameter Determination; Parenteral Drug Association: Sevilla, Spain, 2018.

119. Gronemeyer, P.; Ditz, R.; Strube, J. DoE based integration approach of upstream and downstream processing regarding HCP and ATPE as harvest operation. Biochem. Eng. J. 2016, 113, 158-166. [CrossRef]

120. Meyer, U.A.; Zanger, U.M.; Schwab, M. Omics and drug response. Annu. Rev. Pharmacol. Toxicol. 2013, 53, 475-502. [CrossRef] [PubMed]

121. Schaub, J.; Clemens, C.; Kaufmann, H.; Schulz, T.W. Advancing Biopharmaceutical Process Development by System-Level Data. Analysis and Integration of Omics Data. In Genomics and Systems Biology of Mammalian Cell Culture; Hu, W.S., Zeng, A.-P., Eds.; Springer: Berlin/Heidelberg, Germany, 2012; pp. 133-163. 
122. Schaub, J.; Clemens, C.; Schorn, P.; Hildebrandt, T.; Rust, W.; Mennerich, D.; Kaufmann, H.; Schulz, T.W. $\mathrm{CHO}$ gene expression profiling in biopharmaceutical process analysis and design. Biotechnol. Bioeng. 2010, 105, 431-438. [CrossRef] [PubMed]

123. Hu, W.S.; Zeng, A.-P. (Eds.) Genomics and Systems Biology of Mammalian Cell Culture; Springer: Berlin/ Heidelberg, Germany, 2012.

124. Wiesel, A.; Schmidt-Traub, H.; Lenz, J.; Strube, J. Modellierung der Trennung von Mehrkomponentensystemen mittels Gradientenelution in der präparativen Ionenaustausch- Chromatographie. Chem. Ing. Tech. 2002, 74, 677. [CrossRef]

125. Sixt, M.; Strube, J. Pressurized hot water extraction of 10-deacetylbaccatin III from yew for industrial application. Resour-Effic. Technol. 2017. [CrossRef]

126. Koudous, I.; Sixt, M.; Strube, J. Model-Based Systematic Interpretation of the Extraction and Purification of 10-Deacetylbaccatin III from Taxus baccata; Berichte aus dem Julius Kühn-Institut: Quedlinburg, Germany, 2016.

127. Sixt, M.; Strube, J. Systematic and Model-Assisted Evaluation of Solvent Based- or Pressurized Hot Water Extraction for the Extraction of Artemisinin from Artemisia annua L. Processes 2017, 5, 86. [CrossRef]

128. Sixt, M.; Schmidt, A.; Mestmäcker, F.; Huter, M.; Uhlenbrock, L.; Strube, J. Systematic and Model-Assisted Process Design for the Extraction and Purification of Artemisinin from Artemisia annua L.-Part I: Conceptual Process Design and Cost Estimation. Processes 2018, 6, 161. [CrossRef]

129. Schmidt, A.; Sixt, M.; Huter, M.; Mestmäcker, F.; Strube, J. Systematic and Model-Assisted Process Design for the Extraction and Purification of Artemisinin from Artemisia annua L.-Part II: Model-Based Design of Agitated and Packed Columns for Multistage Extraction and Scrubbing. Processes 2018, 6, 179. [CrossRef]

130. Mestmäcker, F.; Schmidt, A.; Huter, M.; Sixt, M.; Strube, J. Systematic and Model-Assisted Process Design for the Extraction and Purification of Artemisinin from Artemisia annua L.-Part III: Chromatographic Purification. Processes 2018, 6, 180. [CrossRef]

131. Huter, M.; Schmidt, A.; Mestmäcker, F.; Sixt, M.; Strube, J. Systematic and Model-Assisted Process Design for the Extraction and Purification of Artemisinin from Artemisia annua L.-Part IV: Crystallization. Processes 2018, 6, 181. [CrossRef]

132. Zobel, S.; Helling, C.; Ditz, R.; Strube, J. Design and Operation of Continuous Countercurrent Chromatography in Biotechnological Production. Ind. Eng. Chem. Res. 2014, 53, 9169-9185. [CrossRef]

133. Schmidt, A.; Strube, J. Application and Fundamentals of Liquid-Liquid Extraction Processes: Purification of Biologicals, Botanicals, and Strategic Metals. In Encyclopedia of Chemical Technology; Kirk, R.E., Othmer, D.F., Eds.; Wiley: New York, NY, USA, 2003; pp. 1-52.

134. Sixt, M.; Gudi, G.; Schulz, H.; Strube, J. In-line Raman spectroscopy and advanced process control for the extraction of anethole and fenchone from fennel (Foeniculum vulgare L. MILL.). Comptes Rendus Chim. 2018, 21,97-103. [CrossRef]

135. Gudi, G.; Krähmer, A.; Koudous, I.; Strube, J.; Schulz, H. Infrared and Raman spectroscopic methods for characterization of Taxus baccata L.-Improved taxane isolation by accelerated quality control and process surveillance. Talanta 2015, 143, 42-49. [CrossRef] [PubMed]

136. Uhlenbrock, L.; Sixt, M.; Strube, J. Quality-by-Design (QbD) process evaluation for phytopharmaceuticals on the example of 10-deacetylbaccatin III from yew. Resour-Effic. Technol. 2017. [CrossRef]

137. CMC Biotech Working Group. A-Mab: A Case Study in Bioprocess Development. Available online: http: / / www.casss.org/?page=286 (accessed on 17 November 2018).

138. CMC-Vaccines Working Group. A-VAX: Applying Quality by Design to Vaccines. Available online: http:/ / qbdworks.com/wp-content/uploads/2014/06/a-vax-applying-qbd-to-vaccines.pdf (accessed on 17 November 2018).

139. Zobel-Roos, S.; Mouellef, M.; Siemers, C.; Strube, J. Process Analytical Approach towards Quality Controlled Process Automation for the Downstream of Protein Mixtures by Inline Concentration Measurements Based on Ultraviolet/Visible Light (UV/VIS) Spectral Analysis. Antibodies 2017, 6, 24. [CrossRef]

140. Zobel-Roos, S.; Stein, D.; Strube, J. Evaluation of Continuous Membrane Chromatography Concepts with an Enhanced Process Simulation Approach. Antibodies 2018, 7, 13. [CrossRef]

141. Schwellenbach, J.; Zobel, S.; Taft, F.; Villain, L.; Strube, J. Purification of Monoclonal Antibodies Using a Fiber Based Cation-Exchange Stationary Phase: Parameter Determination and Modeling. Bioengineering 2016, 3, 24. [CrossRef] 
142. Mahler, A. Die Reifeprüfung. Der Spiegel. 13 October 2016, pp. 74-78. Available online: https:/ / magazin. spiegel.de/SP/2018/42/159904415/index.html (accessed on 7 November 2018).

143. Bardt, H.; Bertenrath, R.; Demary, V.; Fritsch, M.; Grömling, M.; Klös, H.-P.; Kolev, G.V.; Kroker, R.; Lichtblau, K.; Matthes, J.; et al. Wohlstand in der Digitalen Welt. Erster IW-Strukturbericht; Institut der deutschen Wirtschaft Medien GmbH: Köln, Germany, 2016. 